UNIVERSIDADE DE SÃO PAULO

FACULDADE DE ECONOMIA, ADMINISTRAÇÃO E CONTABILIDADE DEPARTAMENTO DE ECONOMIA

PROGRAMA DE PÓS-GRADUAÇÃO EM ECONOMIA

DECISÃO DAS EMPRESAS DE REALIZAR UM IPO E IMPLICAÇÕES SOBRE DESEMPENHO: UMA ANÁLISE DA EXPERIÊNCIA BRASILEIRA

André Zilio

Orientador: Prof. Dr. Dante Mendes Aldrighi 
Prof. Dr. João Grandino Rodas Reitor da Universidade de São Paulo

Prof. Dr. Reinaldo Guerreiro

Diretor da Faculdade de Economia, Administração e Contabilidade

Prof. ${ }^{\text {a }}$ Dra. Elizabeth Maria Mercier Querido Farina

Chefe do Departamento de Economia

Prof. Dr. Pedro Garcia Duarte

Coordenador do Programa de Pós-Graduação em Economia 
ANDRÉ ZILIO

\title{
DECISÃO DAS EMPRESAS DE REALIZAR UM IPO E IMPLICAÇÕES SOBRE DESEMPENHO: UMA ANÁLISE DA EXPERIÊNCIA BRASILEIRA
}

\author{
Dissertação apresentada ao Departamento de \\ Economia da Faculdade de Economia, \\ Administração e Contabilidade da \\ Universidade de São Paulo como requisito \\ para obtenção do título de Mestre em Ciências.
}

Orientador: Prof. Dr. Dante Mendes Aldrighi

\section{Versão Corrigida}

(versão original encontra-se disponível na Faculdade de Economia, Administração e Contabilidade)

\section{SÃO PAULO}




\section{FICHA CATALOGRÁFICA}

\section{Elaborada pela Seção de Processamento Técnico do SBD/FEA/USP}

\section{Zilio, André}

Decisão das empresas de realizar um IPO e implicações sobre desempenho: uma análise da experiência brasileira / André Zilio. -- São Paulo, 2012. $55 \mathrm{p}$

Dissertação (Mestrado) - Universidade de São Paulo, 2012. Orientador: Dante Mendes Aldrighi.

1. Finanças das empresas 2. Mercado de capitais 3. Investimentos 4. Ações I. Universidade de São Paulo. Faculdade de Economia, Administração e Contabilidade. II. Título. 
Aos meus amigos e família 


\section{AGRADECIMENTOS}

Fazer o mestrado em economia em uma universidade de ponta sempre foi um dos meus grandes objetivos. Esta jornada começou há mais de três anos, quando ainda em Porto Alegre, eu e meus amigos Marmitt e Oscar decidimos, de última hora, nos mudarmos para São Paulo para nos prepararmos à tão temida prova da ANPEC. Foi um ano de muita dedicação, mas como não poderia deixar de ser, de muitas risadas. Foi naquela época que conhecemos a Esmeralda, a Lucineide, o Júlio, o Mateus, e principalmente, o Carinha.

Começo agradecendo ao meu orientador, Dante Mendes Aldrighi, que se dispôs a ser meu novo orientador após eu já ter realizado minha qualificação em um tema completamente distinto deste trabalho. Como membro da banca de qualificação, seu comprometimento e integridade intelectual me cativaram para realização deste trabalho sob sua tutela. Meus sinceros agradecimentos pela sugestão do novo tema, que foi o pontapé inicial deste trabalho, e por toda a paciência, atenção e sugestões dadas ao longo desta jornada.

Agradeço ao meu colega e grande amigo Victor Westrupp, pelo inestimável auxílio na elaboração dos códigos de Stata e nas sugestões de estimações que foram imprescindíveis para a realização deste trabalho. Desejo a você muito sucesso nesta nova jornada do PhD.

Agradeço também a todos meus colegas de IPE-USP, em especial à turma do Partidinho Copero. Este grupo de amigos formado por mim, Cegonha, Eduardo, Gato, Heleno, Luis, Marcel, Marião, Paulo, Piti, Pino, Sérgio e, posteriormente, Victor, foi o principal pilar para que a rotina inicial de estudos fosse mais agradável. Foram diversas as vezes que nos reunimos para estudar, mas também (bGIROante) frequentes as oportunidades que fizemos festas, jogamos poker, bejewelled ou bomberman. Vocês foram os melhores colegas que poderia escolher. Não são apenas colegas e amigos: considero vocês como irmãos que levarei para a vida toda.

Como não poderia deixar de ser, agradeço aos membros da família V10 por todo apoio e conhecimento que adquiri nessa instituição. Obviamente, ao irmão André 
Mazini (que conheci nos tempos de researcher do GV-CEF) por todos os momentos que passamos juntos ao longo destes dois últimos anos, sejam eles na farpagem ou na lisura.

Agradeço à minha amiga Cristiane (não falei que ia te agradecer?) pela disponibilização dos dados da Economática e por ter tirado diversas dúvidas que referem-se ao mercado de capitais brasileiro. Te adoro - apesar da constante falta de paciência.

Mesmo não tendo contribuído para realização deste trabalho, agradeço à francesada (a.k.a. french crew) que conheci em 2012. Em especial, à Raphaelle, Noemie, Helene e Damien (o terror do Big House), que foram pessoas que marcaram minha vida para sempre. Sinto muito a falta de vocês, mas tenho certeza que voltaremos a nos ver em breve.

Ao meu grande amigo Baldusco, pelos excelentes momentos que passamos juntos ao longo dos tempos de estudante de graduação na UFRGS. Te desejo todo sucesso na Alemanha.

Finalmente, agradeço à Leda e Luiz, os melhores pais que eu poderia escolher. Sem o apoio de vocês eu jamais estaria onde estou. Serei eternamente grato por terem acreditado nos meus sonhos e por terem moldado meus valores e caráter do jeito que hoje são. Amo vocês. 
"Investing is simple, but not easy" 


\section{RESUMO}

Este trabalho focaliza os fatores que influenciam a decisão das empresas de realizar uma oferta pública inicial de ações (IPO) e as implicações sobre o desempenho operacional ex-post. Por meio da construção de um banco de dados de empresas brasileiras de capital aberto e fechado relativos ao período entre 2002 e 2010, estimamos modelos econométricos cujos resultados sugerem que as empresas que realizaram IPO eram menores e mais endividadas e apresentavam maiores taxas de rentabilidade, investimento e crescimento. Há evidências, ainda, de que exploraram as circunstâncias favoráveis de preços das ações das empresas já listadas nos setores em que operavam. Para compararmos o desempenho operacional ex-post das empresas que realizaram IPO com o das que se mantiveram fechadas, recorremos à metodologia do propensity score matching. Encontramos evidências robustas de que os investimentos das empresas que listaram na bolsa nesse período são superiores aos das que permaneceram com o capital fechado. Para as demais variáveis de desempenho (rentabilidade, eficiência e endividamento), os resultados não revelaram diferenças significativas entre as empresas desses dois grupos. Essa evidência combinada com a observação de uma relação elevada entre valor de mercado e valor contábil das empresas já listadas do mesmo setor de atividade no momento do IPO pode indicar que a abertura de capital associa-se às exigências de funding para investimentos futuros. 


\begin{abstract}
We analyze the factors that influenced some Brazilian firms to conduct an IPO over the 2002-2010 period as well as the implications on their ex-post operational performance. Using an unique database composed of private and public companies, we estimated a logit model, whose results suggest that the firms that conducted IPOs were smaller, more leveraged, and more profitable, grew at a faster pace, and presented and showed higher investment rates. Furthermore, they tended to explore the favorable equity market conditions of the already listed companies belonging to the same industries where they operated. To compare the ex-post operating performance of the companies that performed an IPO with those that remained private, we used the propensity score matching method. We found robust evidence of higher investment in IPO companies, whereas the results for the other variables (profitability, efficiency and leverage) do not suggest any difference between thes two groups of companies. This finding coupled with the evidence of high stock prices of the already listed companies belonging to the same corresponding industry during the IPO may indicate that the decision to go public is related to funding requirements for undertaking future investments.
\end{abstract}




\section{SUMÁRIO}

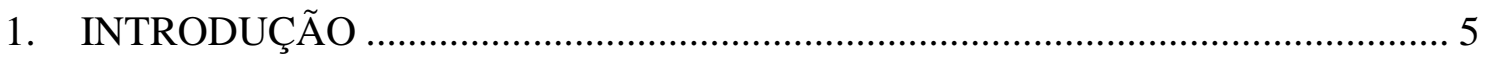

2. REVISÃO DA LITERATURA.................................................................... 9

2.1. Abertura de capital e fatores ex-ante ………………................................... 9

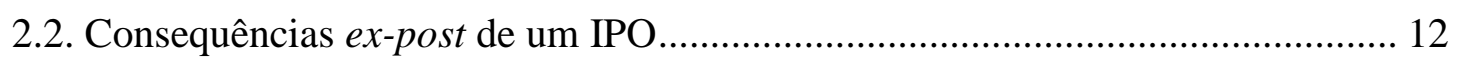

2.3. Teorias que explicam a redução na performance.................................................. 17

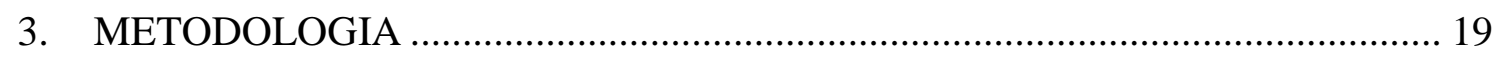

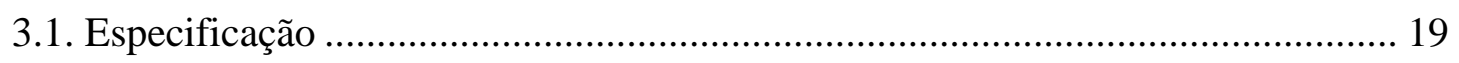

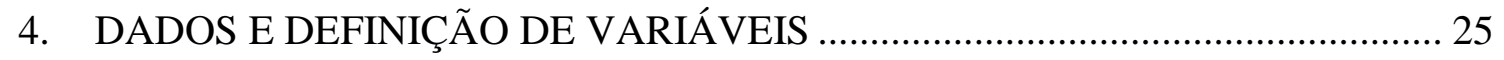

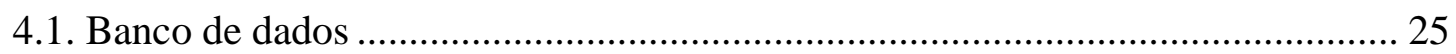

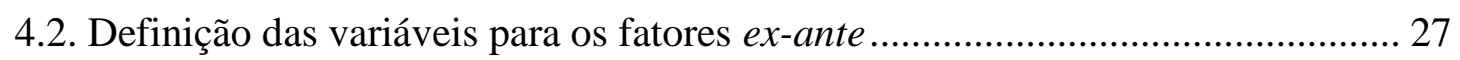

4.3. Definição das variáveis para as consequências ex-post ....................................... 29

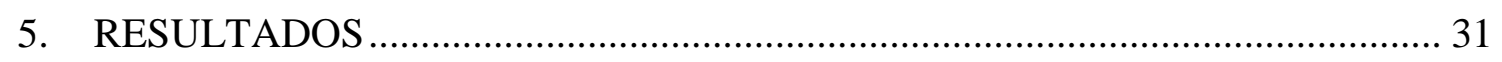

5.1. Fatores determinantes da decisão de realizar IPO ................................................ 31

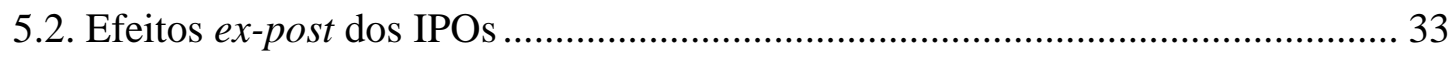

5.3. Análise de desempenho segundo a metodologia do propensity score matching. 35

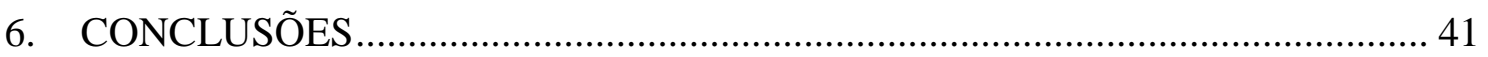

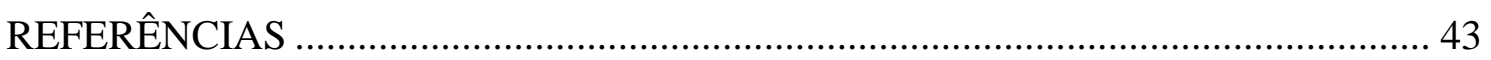

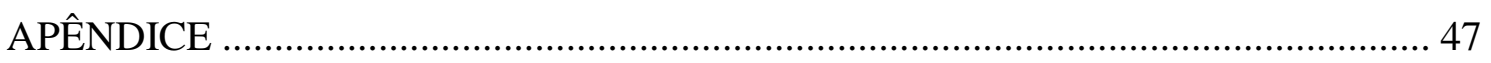




\section{LISTA DE TABELAS}

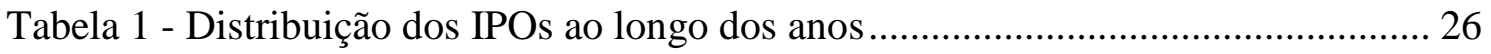

Tabela 2 - Distribuição dos setores em 2002-2010 ….................................................. 27

Tabela 3 - Definição das variáveis de performance ……................................................ 29

Tabela 4 - Modelos Logit de determinação ex-ante de IPO em 2002-2010 .................... 32 


\section{LISTA DE GRÁFICOS}

Gráfico 1- Desempenho operacional dos IPOs realizados em 2004-2007 34 


\section{INTRODUÇÃO}

A partir de 2004, houve uma retomada das ofertas públicas iniciais (IPOs, iniciais dessas palavras em inglês) de ações de empresas no Brasil. Somente em 2007, 64 empresas passaram a ter suas ações negociadas na bolsa brasileira, ${ }^{1}$ captando um montante de $\mathrm{R} \$ 55$ bilhões.

Os estudos dos IPOs que utilizam dados financeiros das companhias concentram-se em empresas de países desenvolvidos e focalizam sobretudo os fatores que influenciam a decisão de realizá-los e o impacto sobre o desempenho operacional ex-post das empresas. ${ }^{2}$ Há evidências robustas dessa literatura em dois aspectos: as condições do mercado de ações afetam o timing do IPO e o desempenho operacional das empresas piora após o IPO. Para os demais países, Brasil em particular, a pesquisa sobre IPOs é escassa e limitada a investigações de natureza descritiva. Como tentativa de reduzir essa lacuna, esta dissertação analisa os fatores que influenciaram a decisão das empresas de abrir o capital e o efeito dessa decisão sobre seu desempenho operacional. Para isso, estimamos modelos econométricos a partir de uma base de dados sobre empresas de

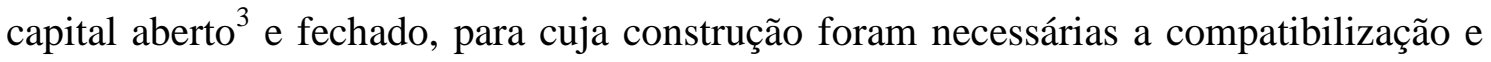
integração de dados provenientes de fontes primárias diversas. As evidências encontradas sugerem que as empresas cujos IPOs se realizaram entre 2002 e 2010 eram menores e mais endividadas, apresentaram antes do IPO crescimento rápido, maior rentabilidade e taxas mais elevadas de investimento, e exploraram as circunstâncias favoráveis de preços das ações das empresas listadas dos setores em que operavam. Enquanto esses resultados sobre os determinantes de IPOs estão em acordo com os da literatura, as evidências que encontramos para desempenho pós-IPO dela divergem. Comparando empresas que abriram capital com as que permaneceram fechadas, não observamos diferenças nas medidas de lucratividade, eficiência e endividamento. Em contrapartida, as empresas que lançaram IPOs elevaram os investimentos em capital fixo relativamente às demais, resultado convergente com as evidências para IPOs nos EUA (Brau, 2010) e distinto do encontrado por Pagano et al. (1998) para empresas italianas.

\footnotetext{
${ }^{1}$ No Brasil as empresas negociam suas ações na Bolsa de Valores, Mercadorias e Futuros de São Paulo (BM\&FBovespa), resultado da fusão da Bolsa de Valores de São Paulo (Bovespa) e da Bolsa de Mercadorias e Futuros (BM\&F).

${ }^{2}$ Ver Brau (2010).

${ }^{3}$ Neste trabalho, o termo "empresas de capital aberto" refere-se apenas às companhias que realizaram emissão de ações na bolsa de valores. Este termo não é empregado às empresas que emitiram debêntures ou dívida.
} 
A evidência de uma relação positiva entre a probabilidade de ocorrência de IPOs nas empresas e a mediana do valuation das empresas já listadas dos correspondentes setores permitia duas interpretações: market timing ou expectativas favoráveis para novos investimentos. A primeira hipótese credita os IPOs ao interesse dos empresários de explorar a janela de oportunidade aberta pela percepção de sobrevalorização das ações das empresas do setor em que respectivamente operam. Na segunda possibilidade, a decisão de IPO decorreria da necessidade de funding para investimentos futuros cujas expectativas de retorno são promissoras. Uma vez que observamos um aumento nos investimentos após os IPOs, inferimos que a motivação das empresas da nossa amostra estava associada a boas oportunidades de investimento no futuro.

Acreditamos que esta dissertação contribui para a literatura em três aspectos. Primeiro, construímos uma nova base de dados envolvendo variáveis financeiras e contábeis de uma ampla amostra de companhias listadas e não-listadas na bolsa, o que nos permitiu realizar estimativas econométricas para testar os fatores determinantes dos IPOs e averiguar a ocorrência de mudanças em algumas variáveis de desempenho após o IPO. Poucos países, entre os quais não se incluem os Estados Unidos, dispõem de dados detalhados de empresas de capital fechado (ver Brau, 2010). Tivemos acesso a uma base de dados de empresas de capital fechado e aberto da Revista Exame - Melhores \& Maiores, a qual integramos a uma outra base de dados de empresas de capital aberto mais completa. Após o esforço de compatibilização, a base de dados resultante acabou sendo composta de 824 empresas, das quais 98 realizaram IPOs no período analisado de nove anos $(2002$ - 2010). Vale mencionar que esse período compreende momentos de expansão da economia, nos quais se observa intensa emissão de IPOs, e de desaceleração, em que o mercado de capitais se retrai.

A segunda contribuição diz respeito à metodologia utilizada para mensurar o desempenho ex-post dos IPOs. Ao invés dos métodos convencionais de pareamento (matching), empregamos o propensity score matching (PSM), que opera pareamentos multidimensionais. Por meio dos diversos algoritmos fornecidos por esse procedimento metodológico, calculamos o efeito médio do tratamento nos "tratados" (average treatment effect on the treated, ATT) para mensurar a diferença de desempenho ex-post entre empresas que abriram capital e as que permaneceram com capital fechado. 
Por fim, a análise sobre os fatores que influenciam a decisão das empresas de lançar IPOs bem como sobre o desempenho operacional pós-IPO, até onde sabemos, nunca antes havia sido empreendida tendo como foco empresas brasileiras, o que permitirá comparações com a escassa literatura sobre a experiência de outros países. Sobre o primeiro tema, os resultados da regressão logística, robustos e significativos, mostraram-se em consonância com a literatura internacional. A estimação do desempenho ex-post das empresas que realizaram IPO por meio do PSM, por sua vez, produziu resultados que destoam dos observados por Pagano, Panetta e Zingales (1998) para empresas italianas.

Além desta introdução, a dissertação se estrutura em outros seis capítulos. No capítulo 2 fazemos uma revisão concisa da literatura pertinente, na qual discutimos as evidências encontradas sobre IPOs e as teorias que buscam explicá-las. No capítulo 3 descrevemos a metodologia de PSM, utilizada para estimar o desempenho ex-post, no capítulo seguinte apresentamos a base de dados e definimos as variáveis, no capítulo 5 analisamos os resultados, e no capítulo 6 concluímos. 


\section{REVISÃO DA LITERATURA}

\subsection{Abertura de capital e fatores ex-ante}

Empresas com ações negociadas em bolsa de valores apresentam diversas vantagens: disponibilidade de uma fonte adicional de captação de recursos, maior poder de barganha vis-à-vis bancos, acesso à participação no capital de investidores de menor porte, possibilidade de maior diversificação de risco e liquidez dos proprietários, valuation pelo mercado (facilitando a venda da companhia e a aquisição de outras empresas), disciplina imposta pelo mercado de capitais, e maior exigência de transparência estabelecida pelos órgãos reguladores (ver Celikyurt et al., 2010).

Entretanto, este processo também envolve custos, que são tanto indiretos como diretos. O primeiro caso tem como principal referência o desconto observado no preço das ações na oferta pública relativamente ao preço que vigora no mercado secundário ${ }^{4}$. Além disso, essas empresas estão sujeitas à possibilidade de uma aquisição hostil por parte de outra firma. Os custos diretos estão relacionados aos gastos com IPO (como pagamentos ao underwritter e consultores jurídicos etc.) e manutenção da listagem na bolsa (despesas administrativas, auditoria de relatórios etc.).

De uma maneira geral, os estudos sobre IPO focalizam quatro temas: i) retornos de curto, médio e longo prazo das ações das firmas que fizeram emissão primária de ações; ii) o processo de formação de preços do IPO e o papel do underwriter na emissão, ${ }^{5}$ com ênfase nos potenciais conflitos de agência entre bancos de investimentos, empresas emissoras e investidores; iii) as motivações sobre a abertura de capital; e iv) desempenho operacional ex-post de empresas que realizaram IPO. Esta dissertação trata desses dois últimos aspectos à luz da experiência de uma amostra de empresas brasileiras.

Apesar de existirem diversas hipóteses sobre a motivação para a abertura de capital das empresas, a evidência empírica a respeito desses fatores ainda é limitada, principalmente devido à falta de dados disponíveis de empresas privadas - que são

\footnotetext{
${ }^{4}$ Este fenômeno é conhecido na literatura como underpricing. Para mais informações, ver Loughran e Ritter, 2004.

${ }^{5} \mathrm{O}$ underwriter de um IPO, um banco de investimento, tem como atribuição conjugar os interesses dos investidores e das empresas emissoras, coordenar os procedimentos de registro junto à CVM, definir o timing da oferta, conduzir o processo de formação de preço, e realizar o plano de distribuição.
} 
necessários para a comparação de novos IPOs e empresas que mantiveram o capital fechado para isolar os fatores que afetam a decisão das firmas de realizar um IPO. De maneira geral, os estudos seguem três estratégias: i) realização de questionários com executivos das companhias que realizaram IPO; ii) adoção de estratégias que comparem o conjunto de dados entre as empresas que fizeram IPO e suas características pré-IPO; e iii) comparação entre empresas de capital fechado e aberto.

Os tipos de estudos mais encontrados na literatura seguem a segunda linha de pesquisa, enquanto a última categoria é menos frequente. Como a base de dados deste trabalho é composta de companhias abertas e fechadas, seguiremos a última linha de pesquisa referenciada acima.

Em um importante estudo sobre os motivos das firmas abrirem capital, Pagano et al. (1998) apresentam evidências para uma amostra de companhias italianas de que a decisão de efetuar um IPO é motivada sobretudo pela intenção de se promover uma reestruturação do capital e pelo market timing (explorar a janela de oportunidade oferecida pela euforia no mercado acionário, captada pela mediana da relação entre valor de mercado e valor contábil das empresas listadas do setor correspondente). Observando uma redução permanente no investimento e na lucratividade das empresas pós-IPO, os autores sugerem que o coeficiente positivo da variável market-to-book ratio $^{6}$ do setor indica a tentativa dos gestores de explorar momentos de euforia no mercado de ações, descartando a interpretação de que este movimento seria reflexo da maior necessidade de investimento em setores com oportunidades de crescimento. Observam também que firmas mais antigas e maiores têm maior probabilidade de realizarem IPO, o que pode significar que idade e escala operam como proxies para reputação: empresas emergentes e pequenas seriam pouco conhecidas e, portanto, enfrentariam maiores problemas de seleção adversa. No caso de IPOs de empresas pertencentes a um grupo econômico, tamanho não se mostra relevante, pois pode haver spillover de reputação da empresa-matriz e esta assumir os custos fixos de listagem.

Por sua vez, Celikyurt et al. (2010) analisam as atividades de aquisição das empresas norte-americanas que realizaram IPO no período 1994-2004. Encontram alta incidência

\footnotetext{
${ }^{6}$ Market-to-book-ratio é um indicador financeiro utilizado para comparar o valor de mercado da companhia com seu valor contábil. O objetivo desta variável é identificar empresas sobrevalorizadas ou subvalorizadas.
} 
da participação dessas empresas no ramo de fusões e aquisições, sobretudo de aquisições no primeiro ano após o IPO. Um importante resultado do estudo é que nos cinco anos após o IPO essas empresas utilizam mais seus recursos financeiros na aquisição de ativos de outras empresas do que na atividade de pesquisa, investimento em capital fixo, ou até mesmo os dois combinados. O resultado acaba sugerindo que as IPOs crescem mais através da atividade de M\&A do que investimento interno em P\&D ou Capex.

Devido à falta de dados de companhias fechadas nos Estados Unidos, muitos pesquisadores optaram pela utilização de questionários para guiarem suas pesquisas. Buscando verificar a relevância empírica de diversas teorias acerca dos motivos de abertura de capital, Brau (2010) fez uma pesquisa com CFOs de 984 IPOs nos períodos 1996-1998 e 2000-2002 e mostrou que apenas 3 das 31 perguntas tiveram aceitação de mais de $75 \%$ dos executivos como ponto vantajoso na condução de um IPO: i) geração de financiamento para crescimento de longo prazo $(86,8 \%)$, ii) geração de financiamento para crescimento imediato $(86,8 \%)$, iii) aumento de liquidez $(82,5 \%)$.

Por outro lado, apenas 3,8\% desses CFOs concordaram que um benefício da realização de IPO é de permitir o desenvestimento do proprietário original. Essa baixa aceitação dessa pergunta revela uma das maiores críticas à utilização de questionários. Mesmo se os fundadores utilizarem os recursos do IPO para de fato desinvestirem, o executivo que responder o questionário pode se sentir na obrigação de não falar a verdade a respeito, seja devido a futuros processos, ou a sinais negativos emitidos aos acionistas e mercado.

No Brasil, Schiozer et al. (2010) avaliam os motivos que levaram os bancos a abrirem capital no período 2005-2007. Ao contrário do que fora encontrado por Pagano et al. (1998), os autores mostram que são as melhores oportunidades de crescimento relativamente a seus competidores que geram a decisão dos bancos de realizar um IPO. Especificamente, eles observam que essas empresas financeiras que realizaram IPO encontraram maiores restrições de capital e liquidez, ao mesmo tempo em que apresentaram lucro mais elevado e melhor qualidade de gerenciamento. Esses resultados acabam reforçando a teoria de que empresas abrem capital por motivações econômicas e que as ondas de IPO são consequências do ciclo de negócios, ou seja, de choques nos ambientes econômico, regulatório e tecnológico do setor que em estão inseridas. No que diz respeito ao setor bancário, os autores afirmam que "a decisão da abertura de capital 
é explicada principalmente por oportunidades de crescimento associadas com períodos de alta liquidez na economia, e não por underwritters e controladores desses bancos buscarem uma janela de oportunidade no intuito de tomar vantagem de ações sobrevalorizadas".

Aldrighi et al. (2009) investigaram os principais determinantes da decisão de realizar IPO no Brasil no período 2002-2007. Eles encontram que empresas maiores, com alto crescimento, mais lucrativas e que investem mais possuem maior probabilidade de abrir o capital. Diversificação e reestruturação financeira não aparentam ser motivações para os IPOs. Como o modelo econométrico não dá suporte à hipótese de reestruturação financeira, eles verificaram prospectos de diversos IPOs e observaram uma pequena parcela dos recursos obtidos na abertura de capital na redução de alavancagem. Em contrapartida, ao contrário do que fora observado por Pagano et al. (1998), o resultado da relação preço/lucro setorial (principal motivador da realização de IPO na economia italiana) não apresenta significância estatística.

\subsection{Consequências ex-post de um IPO}

O declínio da performance operacional pós-IPO tem sido extensivamente documentado na literatura. Os primeiros a averiguar tal fenômeno foram Jain e Kini (1994). Utilizando uma amostra de 2.125 IPOs dos EUA de 1976 a 1988, observam que o desempenho operacional diminuiu significantemente no ano em que a firma fez o IPO e nos três anos seguintes. Esses resultados permaneceram robustos a diversas medidas de performance, seja através de lucro ou fluxo de caixa.

Além do resultado da piora de desempenho, Jain e Kini (1994) encontraram que este fenômeno vem acompanhado de um elevado crescimento nas vendas e investimentos relativamente a firmas que pertencem ao mesmo setor. Isso implica que o declínio da performance operacional das empresas que realizaram o IPO não pode ser atribuido à diminuição nas vendas ou investimentos pós-IPO. Além disso, é verificado que em firmas que venderam nos IPOs apenas uma pequena parcela do seu capital geralmente demonstraram performance superior relativamente a outras firmas, mesmo ajustando pelo setor em que estão inseridas. 
Especificamente, utilizando como base o ano -1 (ano que precedeu a abertura de capital), os autores analisaram a mudança na mediana dos retornos operacionais dos ativos com e sem ajuste do setor em que estão inseridos. Para os anos $0,+1,+2$ e +3 , as mudanças foram respectivamente de $-3,58 \%,-7,60 \%,-10,53 \%$ e $-9,09 \%$, sem ajuste de indústria (todos significativamente diferentes de zero ao nível de 0,01 pelo teste de Wilcoxon). Ajustando pela indústria, temos um resultado similar, com variação de $2,91 \%,-6,24 \%,-8,12 \%$ e $-6,81 \%$ (todos significantes ao nível de 0,01 ), o que implica que a queda de desempenho não pode ser atribuida aos efeitos do setor em que as empresas estão inseridas. Os autores ressaltam que estudos anteriores haviam encontrado baixo retorno no mercado de ações para firmas que fizeram IPO por vários anos subsequentes pós abertura de capital. Aparentemente empresas que fizeram IPO são precificadas com a expectativa de que as margens de lucro irão crescer além dos níveis pré-IPO, enquanto que na realidade elas caem ao longo do tempo.

O resultado encontrado no artigo descrito acima despertou o interesse de diversos outros pesquisadores. Mikkelson et al. (1997) averiguam 286 empresas norte-americanas que realizaram IPO no período que data de 1980 a 1983. Para mensurar performance operacional, eles utilizaram o lucro operacional antes da depreciação, juros, impostos e itens extraordinários dividido pelos ativos do final do ano. Como essa medida de retorno operacional pode criar um viés de baixa, uma vez que nos IPOs tipicamente ocorre um aumento substancial nos ativos, eles também examinam lucro operacional dividido por vendas.

Para toda a amostra analisada, Mikkelson et al. (1997) encontram uma queda no desempenho operacional das empresas que realizaram IPO Essa redução é mais evidente entre os anos -1 e 0 e entre 0 e 1 , onde 0 equivale ao ano da realização do IPO. Eles também analisam medidas ajustadas de desempenho mediante a utilização de três controles: (i) setor em que estão inseridas, (ii) tamanho da firma e do setor; (iii) setor e performance. $^{7}$ Da mesma forma, os resultados apontam que firmas que abriram capital no período 1980-1983 demonstraram medidas bastante elevadas de performance no ano anterior à efetivação do IPO. Para todas as medidas de desempenho, sejam elas ajustadas ou não, a mediana da performance operacional mensurada por lucro operacional dividido por ativos ou por vendas torna-se negativa após o IPO. Entretanto,

\footnotetext{
${ }^{7}$ Esse controle é realizado através da subtração da mediana do retorno operacional contemporâneo do grupo de controle.
} 
essa queda está restrita ao primeiro ano de transação pública de ações, não havendo pioras adicionais nos dez anos posteriores de negociação das ações.

Um dos trabalhos precursores a averiguar se o fenômeno de redução de performance observado na economia norte-americana verificava-se em outros países foi desenvolvido por Pagano et al. (1998). Como discutido anteriormente, os autores analisam dados da economia italiana de 1982 a 1992, buscando responder quais são os principais determinantes na decisão de abertura de capital e como se configura o desempenho operacional das firmas após o IPO.

Para analisar as consequências ex-post, os autores estimam regressões em dados de painel com efeito fixo, onde o efeito da decisão das empresas abrirem capital é captado por variáveis dummies para o ano do IPO e para os três anos subsequentes. Para todas as variáveis de performance analisadas, eles utilizam a seguinte especificação econométrica:

$y_{i t}=\alpha+\sum_{j=0}^{3} \beta_{j} I P O_{t-j}+\beta_{4} I P O_{t-n}+\sum_{j=0}^{3} \gamma_{j} Q U O T_{t-j}+u_{i}+d_{t}+\epsilon_{i t}$

em que $I P O_{t-j}$ são variáveis dummy iguais a um se o ano $t$-j foi o ano do IPO, $I P O_{t-n}$ é uma variável dummy igual a um se o IPO aconteceu há mais de três anos, $Q U O T_{t-j}$ são variáveis qualitativas iguais a um se a firma $i$ safisfez os pré-requisitos de listagem no ano $t-j$, e por fim, $u_{i}$ e $d_{t}$ são, respectivamente, efeitos específicos da firma e do ano.

Através da especificação acima, da mesma forma como documentado para os EUA, as empresas italianas que realizaram IPO mostraram piora na performance operacional após a abertura de capital. Utilizando ROA (EBITDA sobre ativo total) como medida de lucratividade, os autores encontram variação de $-8 \%$ no ano zero (ano do IPO) e declínio praticamente linear nos anos subseqüentes: $-15 \%,-20 \%,-28 \%$ e $-31 \%$ para os anos $+1,+2,+3$ e $>3$, respectivamente.

Mensurando investimento através da variável Capex, os autores encontram um resultado que consideram surpreendente: a decisão de uma empresa abrir seu capital implica uma queda permanente nos investimentos dois anos após o IPO. As variações nos investimentos são de $23 \%, 16 \%,-17 \%,-41 \%$ e $-42 \%$ para os anos $0,+1,+2,+3$ e >3, respectivamente. Em relação à alavancagem, os autores verificam uma redução imediata 
de 5,1\% já no ano do IPO. Para os anos subsequentes, a variação é de -3,1\%, -5,4\%, $6,4 \%$ e $-11,6 \%$, resultado que sugere que as empresas abrem capital para reduzir permanentemente a alavancagem.

Os autores também dividem a amostra em empresas independentes e subsidiárias (carve-outs), ${ }^{8}$ onde as independentes compõem aproximadamente $93 \%$ das quase vinte mil empresas da amostra. Os dados de investimento mostram que as firmas independentes abrem capital com o objetivo de reestruturação financeira após um período de investimentos elevados. Já para o caso de IPOs de empresas subsidiárias há uma elevação significativa no investimento após o IPO, com a alavancagem se reduzindo mais lentamente. Isto sugere que, além de permitir que o controlador venda parte de sua participação, o IPO serve para financiar a aquisição de novos investimentos. A conclusão principal referente às consequências ex-post aponta que as empresas independentes não realizam IPO para financiar crescimento e investimentos subsequentes, mas para reequilibrar seus balanços após um período de elevado crescimento e investimento.

Khurshed et al. (2003), analisando IPOs realizados no Reino Unido entre janeiro de 1995 e dezembro de 1999, também encontram evidências de queda na performance operacional após a abertura de capital. Observam que no segmento de listagem convencional da bolsa (Official List) os investimentos decrescem, os ativos crescem e a exposição à dívida geralmente cai de forma permanente após o IPO, indicando uma possível reestruturação do capital. Diferentemente, no segmento mais flexível e composto de empresas menores (o Alternative Investment Market, AIM), ${ }^{9}$ os autores encontram evidências de que as empresas abrem capital para captarem fundos para financiar a expansão - a performance cresce, embora sem significância estatística, e os investimentos aumentam mais do que os ativos, ao mesmo tempo em que o grau de alavancagem não é substancialmente afetado. Os resultados indicam que os primeiros acionistas da companhia não aparentam usar o IPO como oportunidade de desinvestimento, mas como um meio para financiar o crescimento da empresa.

\footnotetext{
${ }^{8}$ Um carve-out é uma espécie de reorganização corporativa, onde uma empresa cria uma subsidiária e realiza seu IPO. Geralmente, $20 \%$ dos ativos dessa subsidiária são oferecidas ao público.

${ }^{9}$ O AIM é organizado como um "Mercado Regulamentado para Troca," o que implica que os documentos para admissão ao AIM não são pré-vetados por uma autoridade de mercado, mas sim por um intermediário financeiro (escolhido pela própria empresa) que é responsável pela garantia de que a firma está apta a participar do mercado acionário. O objetivo dessa flexibilidade é facilitar o ingresso de empresas de menor porte no mercado de capitais.
} 
Khurshed et al. (2003) concluem afirmando que "o AIM é, de fato, o primeiro mercado onde a performance operacional não se deteriora após o IPO”.

Também investigando se ocorre queda no desempenho operacional pós-IPO, Cai e Wei (1997) analisam uma amostra de 180 empresas que realizaram IPO no Japão no período 1971-1992. Os autores encontram evidências de que as principais medidas de performance operacional crescem antes do IPO, atingindo o pico no ano anterior à listagem, para então cair substancialmente após a abertura de capital. Como não encontram relação entre a queda de rentabilidade e a mudança na estrutura de propriedade, apontam que os gestores realizam emissão de ações no período de melhora temporária de desempenho - quando os investidores estão com expectativas otimistas em relação às perspectivas futuras da companhia.

Utilizando a metodologia de propensity score matching (PSM), Chaouani (2010) analisa o efeito do IPO na performance operacional de 3951 empresas francesas (157 IPOs e 3794 não-IPOs) entre 1996 e 2006. Mediante o pareamento de firmas que efetuaram IPO relativamente às que não o fizeram, o autor observa uma queda na performance operacional nas empresas que realizaram IPO. As que não abriram capital destacam-se pela performance bem menos ruim vis-à-vis as IPO para os cinco anos após a abertura de capital. Por exemplo, a medida de performance EBITDA/Ativo total passa de 6,7\% dois anos antes do IPO para 1\% cinco anos após a abertura de capital. Em contrapartida, as firmas pareadas que não o fizeram passam de $7,9 \%$ para $7 \%$ no mesmo período analisado.

Alguns estudos de performance operacional de IPOs foram efetuados para o Brasil. Como exemplo podemos citar Bossolani (2009), que fez a análise da performance das empresas não-financeiras que fizeram IPO no período 2004-2006. O autor verificou crescimento das receitas e redução na alavancagem das mesmas, sugerindo um ambiente de escassez de crédito. Além disso, ele encontrou um resultado que vai contra a literatura internacional: melhora de desempenho operacional após o IPO. Este resultado pode ser decorrente da falta de controle dos efeitos macroeconômicos, já que ele ignora o fato de o período de 2005-2007 ser de abundância de crédito e elevado crescimento, o que pode gerar a falsa impressão de que os resultados foram decorrentes da abertura de capital. 


\subsection{Teorias que explicam a redução na performance}

Como vimos, a literatura aponta uma tendência de queda na performance operacional nas empresas que realizaram IPO. De maneira geral, há duas linhas teóricas que buscam explicar a piora no desempenho (underperformance), a abordagem clássica, que evidencia a presença de assimetria de informações associada à redução de controle dos gestores pós-IPO, e as finanças comportamentais, que remetem a piora no desempenho ao market timing e window dressing.

A teoria clássica enfatiza os custos de agência, onde os gestores tomam decisões subótimas porque, com a abertura do capital, internalizam apenas a parcela dos custos proporcional à sua participação no capital. Já a interpretação das finanças comportamentais recorre ao market timing e/ou ao window dressing. Na abordagem do market timing, os diretores aproveitam a janela de oportunidade (window of opportunity) aberta pelas expectativas excessivamente otimistas dos investidores em relação ao desempenho futuro, expressas na sobrevalorização das ações, e a melhora temporária do desempenho financeiro para lançarem os IPOs (Loughran e Ritter, 1995a). Em um outro trabalho, Loughran e Ritter (1995b) interpretam a evidência de que as empresas emitem ações em períodos de melhora de desempenho financeiro para intencionalmente, e de forma bem-sucedida, explorar a euforia dos investidores. Observam que a maioria das firmas que emitem ações após os IPOs o fazem em seguida a altas substanciais de suas cotações. Para os autores, algumas firmas tentam gerir os rendimentos visando a emissão de ações, enquanto outras exploram oportunisticamente as condições favoráveis do mercado acionário, alheias ao seu controle.

Na perspectiva do market timing, as empresas emitem ações quando suas cotações estão sobrevalorizadas, o que explica duas situações nas quais a teoria da pecking order (Myers, 1984) é inadequada: os baixos retornos das empresas pós-emissão e a emissão de capital acionário quando as empresas teriam outras opções. Em outras palavras, ao contrário da teoria estática da pecking order, segundo a qual há uma ordenação fixa na escolha da fonte de financiamento (recursos internos, dívida e capital de terceiros), na "pecking order dinâmica" a ordenação dessas opções depende das condições do mercado de capital. 
A hipótese da pecking order prevê que as firmas emissoras de ações esgotaram sua capacidade de endividamento. Todavia, Korajczk et al. (1990) apresentam evidências de que a debt ratio tipicamente não aumenta antes da emissão de ações, sugerindo que a piora na capacidade de tomar dívida não é a principal razão da emissão acionária.

$\mathrm{Na}$ visão do market timing, uma empresa sobrevalorizada no mercado emitirá ações para se beneficiar do momento oportuno, aumentando a folga financeira (financial slack). Quando há poucas firmas sobrevalorizadas, ocorrem poucas emissões; diferentemente, havendo muitas firmas sobrevalorizadas, ocorrerão muitas emissões, seguidas de performances operacionais desapontadoras e baixos retornos das ações.

Essas evidências no mercado secundário americano são similares às dos mercados de IPOs em outros países. Loughran e Ritter (1995a) mostram que as ações dos IPOs têm um retorno inferior em $7 \%$ ao ano nos cinco anos após a emissão, enquanto que para as empresas que efetuaram emissão secundária este valor chega a $8 \%$ ao ano. Como destacado na subseção anterior, há uma deterioração da performance operacional das empresas que emitem ações no mercado de capitais. Além disso, as evidências apontam que a performance dos investimentos de empresas que efetuaram emissões secundárias nos EUA, Reino Unido e Japão são muito parecidas. Esses padrões são consistentes com o fato de que má precificação (misvaluation) é um fato comum no mercado de ações.

A segunda vertente das finanças comportamentais que busca explicar a piora no desempenho das firmas que efetuaram IPO é a window dressing. Para induzir os participantes do mercado a efetuarem valuations otimistas, os gestores das empresas podem gerenciar os resultados contábeise e as informações nos prospectos de abertura de capital. Há diversas maneiras pelas quais os gestores podem efetuar esse gerenciamento de desempenho de uma companhia antes da abertura de capital: mediante a "transferência" de lucros de outros períodos, adiando gGIROos com pesquisa e desenvolvimento; através da alocação de custos em maiores períodos de tempo; ou através da redução do crescimento dos salários nos anos anteriores ao IPO. Quando os gestores não conseguem mais ocultar a verdade contábil, os investidores reavaliam a firma para o nível compatível com os fundamentos econômicos efetivos. 


\section{METODOLOGIA}

\subsection{Especificação}

Para tratar do problema de seleção amostral na análise do desempenho ex-post dos IPOs, esta dissertação utiliza a metodologia do PSM, que realiza o pareamento (matching) multidimensional. Trabalhos anteriores, que recorriam ao pareamento simples, apresentavam o problema da "dimensionality curse," ${ }^{10}$ pois para examinar o desempenho dos IPOs comparavam os resultados ex-post das empresas que fizeram IPO com os das empresas que já possuíam capital aberto pareando por variáveis ex-ante, como tamanho, razão market-to-book-value e retornos passados na bolsa.

Neste estudo, utilizaremos a técnica de PSM, proposta inicialmente por Resenbaum e Rubin (1983), que visa reduzir o viés de seleção pela comparação de resultados por meio de variáveis similares de tratamento e controle. Ademais, a estratégia de PSM integra as variáveis econômicas relevantes pré-tratamento em uma única variávelíndice, o propensity score.

Como evidenciado por Caliendo e Kopeinig (2005), a ideia básica de PSM é de encontrar um amplo grupo de não-participantes de determinado evento que são similares aos participantes em todas as características relevantes $X$ pré-tratamento. Feito isso, diferenças nos resultados das variáveis que desejam ser mensuradas podem ser atribuídas ao tratamento - no caso deste estudo, a decisão de realizar IPO.

Neste trabalho, a variável de tratamento é a variável IPO, que assume valores 1 ou 0 , enquanto a estimação da performance operacional ex-post representa o efeito de tratamento, ou treatment effect. Para mensurarmos o efeito da performance operacional no IPO, estimaremos o efeito médio de tratamento nos tratados (average treatment effect on the treated), doravante ATT.

\footnotetext{
${ }^{10}$ Este é um problema que surge quando o vetor de informação $X$ contém duas ou mais variáveis. Suponha que queremos parear um indivíduo $\mathrm{A}$, que possui $X_{1}=(1000,5)$ com indivíduos B ou C, que possuem $X_{2}=(1100,12)$ e $X_{3}=(2000,8)$, respectivamente. Qual dos dois indivíduos não tratados, B ou C, é mais próximo de A? Não há uma resposta óbvia para esta questão: o indivíduo B se aproxima mais de $\mathrm{A}$ em termos da primeira variável, porém se distancia mais em termos da segunda variável. De maneira geral, quando a análise se desenvolve em múltiplas dimensões (isto é, com várias variáveis), não é precisa a noção de proximidade.
} 
Seja $Y_{i l, t}$ a performance operacional da empresa de capital aberto $i$ no período $t$ (a dummy de tratamento é 1) e $Y_{i 0, t}$ a performance operacional da empresa $i$ se continua com o capital fechado no período $t$ (a dummy de tratamento é 0 ). $\mathrm{O}$ efeito de tratamento para a firma $i$, isto é, o impacto de realizar um IPO em sua performance operacional durante o período $t$ é definido como:

$\tau_{i t}=Y_{i 1, t}-Y_{i 0, t}$

Seja $D_{i}=1$ se a firma i realiza IPO e $D_{i}=0$ se a firma i permanece fechada. O efeito de tratamento esperado para a mesma amostra de firmas que realizaram IPOs fica:

$$
\left.\Delta\right|_{D=1}=E\left(\tau_{i t}\right)=E\left(Y_{i 1, t} \mid D_{i}=1\right)-E\left(Y_{i 0, t} \mid D_{i}=1\right)
$$

em que $E\left(Y_{i 1, t} \mid D_{i}=1\right)$ denota a performance operacional média da firma que fez IPO no período de tempo $t$ após a data de abertura de capital e $E\left(Y_{i 0, t} \mid D_{i}=1\right)$ é a performance operacional média da firma que fez IPO no período $t$ se ela não o tivesse feito. O problema em computar o efeito de tratamento em (3) é que não observamos a performance operacional pós-IPO das firmas que realizaram IPO se elas tivessem permanecido com o capital fechado (o problema de missing data). Mas dispondo de um grupo de firmas para efetuar o controle, firmas que não fizeram IPO, estimamos a performance operacional média das firmas que não realizaram IPO durante o período $t$ :

$$
\left.\Delta\right|_{D=1} ^{e}=E\left(Y_{i 1, t} \mid D_{i}=1\right)-E\left(Y_{i 0, t} \mid D_{i}=0\right)
$$

Inferir diretamente o ATT pela equação 4 em um ambiente em que não há aleatoriedade pode gerar erros, pois o grupo de tratamento (firmas com IPO) e o grupo de comparação (firmas sem IPO) podem não pertencer a uma amostra não-aleatória. Se, por exemplo, os fatores que afetam o tratamento também afetam o resultado (performance operacional), utilizar $E\left(Y_{i 0, t} \mid D_{i}=0\right)$ como um substituto de $E\left(Y_{i 1, t} \mid D_{i}=1\right)$ pode implicar um viés sistemático. Para lidar com esse problema de seleção, métodos de pareamento impõem a seguinte suposição de independência condicional, implicando que, dado um grupo de variáveis de controle observáveis, a atribuição ao grupo de controle é aleatório e independe do resultado. 
$\left(Y_{i 1, t}, Y_{i 0, t}\right) \perp D_{i} \| X_{i}$

Onde $X$ é um vetor das características $e x$-ante da firma, e $\perp$ denota independência.

Esta condição é também chamada de ignorable treatment assignment (Rosenbaum e Rubin, 1983) ou selection on observables (Heckman e Robb, 1985). A ideia por trás da suposição de independência condicional é de que, se há informação suficiente a respeito de $X$ sobre a decisão de participação (fatores que determinam a decisão de abertura de capital), pode-se eliminar a correlação entre $\left(Y_{i 1, t}, Y_{i 0, t}\right)$ e $D_{i}$ ao condicioná-las em $X$. O ATT pode então ser computado ao se tirar a média do efeito condicional sobre as variáveis de efeito condicional, isto é:

$\left.\Delta\right|_{D=1}=E_{x}\left\{\left[\left(Y_{i 1, t} \mid X_{i}, D_{i}=1\right)-E\left(Y_{i 0, t} \mid X_{i}, D_{i}=0\right)\right] \mid D_{i}=1\right\}$

Uma forma de estimar a equação (6) é combinar firmas IPO e não-IPO em suas características ex-ante $X_{i}$. O matching em todas as variáveis em $X_{i}$ torna-se impraticável conforme o número de variáveis aumenta. Para solucionar esse problema, Rosenbaum e Rubin (1983) propõem o método do Propensity Score Matching, que reduz o problema de pareamento multidimensional para unidimensional. Ao invés de estimarmos o pareamento no vetor $X$, efetuamos o match na probabilidade de participação $P(X)$. No contexto de um evento de IPO, $P(X)$ é o propensity score ou a probabilidade prevista de uma empresa abrir capital, onde:

$P(X)=\operatorname{Pr}\left(D_{i}=1|| X_{i}\right)$

O ATT pode então ser computado ao tirar-se a média do efeito condicional sobre a probabilidade prevista de realização de IPO (propensity score distribution in the treated group), ou seja,

$\left.\Delta\right|_{D=1}=E_{p(x)}\left\{\left[\left(Y_{i 1, t} \mid P\left(X_{i}\right), D_{i}=1\right)-E\left(Y_{i 0, t} \mid P\left(X_{i}\right), D_{i}=0\right)\right] \mid D_{i}=1\right\}$

O propensity score designa uma probabilidade condicional a uma observação de atribuição ao grupo de tratamento, dado um conjunto de covariáveis. Para implementar o PSM, um modelo empírico tem de ser especificado para derivar o propensity score. 
Neste trabalho, estimamos um modelo logit a respeito da decisão das empresas de abrir o capital condicionada às características das firmas. Outra condição necessária é haver uma probabilidade positiva para uma firma com IPO de encontrar um par no grupo nãoIPO baseado no propensity score.

O processo de estimação do modelo é dividido em quatro passos. Primeiro, estimamos um modelo logit para definirmos as variáveis que afetam a decisão da empresa de abrir capital. Esse modelo é o mesmo empregado na análise dos fatores determinantes para realização de um IPO. Com base no modelo que melhor se adaptar aos dados, obtemos o propensity score.

A segunda etapa consiste em efetuar o pareamento em cada observação do grupo de tratamento (firmas IPO) com o grupo de controle (não-IPOs) baseado no propensity score de cada ano. Para a obtenção desse propensity score, utilizamos o algoritmo Kernel matching. Feito isso, prosseguimos com a estimação dos resultados mediante alternativas de pareamento para obtermos resultados robustos que sejam independentes da metodologia utilizada.

O algoritmo básico de Kernel matching é um estimador de matching não-paramétrico que compara o resultado de cada unidade tratada (IPOs) com a média dos resultados não-tratados (não-IPOs) por meio de uma média ponderada das empresas de capital fechado, com o maior peso sendo dado aos scores mais próximos das empresas que abriram capital. Uma das principais vantagens desse algoritmo é a baixa variância gerada, uma vez que mais informações são utilizadas relativamente a outras estratégias.

Cabe ressaltar que para realizar as estimações, é necessário ordenarmos os dados de maneira aleatória, pois, de acordo com Guo e Fraser (2010), quando uma unidade tratada é encontrada, diversos casos não-tratados (que possuem o mesmo propensity score) podem estar relacionados. Num pareamento realizado 1 a 1 , identificar tais relações depende da ordem em que as variáveis estão ordenadas. Para solucionar o problema, foi gerada uma variável uniforme aleatória, pela qual as variáveis foram ordenadas. 
O terceiro passo é efetuar testes de balanceamento para verificar se a média de cada característica difere entre o grupo de tratamento e o de controle. Caso essas médias das características forem distintas, a hipótese de balanceamento não é satisfeita. Também utilizaremos testes conjuntos para verificar a igualdade das médias em todos as covariáveis nos grupos $D_{i}=1$ e $D_{i}=0$. Se não existirem diferenças estatísticas significativas entre ambos os grupos, podemos proceder com a estimação do efeito de tratamento.

Por fim, serão avaliados os efeitos da decisão de uma empresa ter ações negociadas na $\mathrm{BM} \& \mathrm{FBovespa}$ sobre a performance operacional dessas companhias para cada um dos três primeiros anos após a abertura de capital. Será calculado o ATT para as diversas medidas de desempenho que foram propostas, com seus respectivos erros-padrão gerados mediante o processo de bootstrap. 


\section{DADOS E DEFINIÇÃO DE VARIÁVEIS}

\subsection{Banco de dados}

Utilizamos na pesquisa uma base de dados de 824 empresas brasileiras no período de 2002 a 2010, 98 das quais realizam IPOs e as 726 restantes não o fizeram. Para as empresas de capital aberto, a base de dados provém do software Economática. Para as empresas de capital fechado, a fonte é a base de dados da "Melhores e Maiores" (MM) da Revista Exame.

A Economática fornece dados financeiros de todas as empresas listadas na BM\&FBovespa. Após verificarmos no site da CVM e da BM\&FBovespa quais empresas abriram capital no período 2002-2010, excluímos as demais empresas, listadas antes de 2002.

Diversos IPOs que constavam no site da bolsa de valores não apareciam na base de dados - devido ao cancelamento das ações junto à BM\&FBovespa, fusão com outra empresa ou mudança de nome. ${ }^{11}$. No período 2002-2010, 133 empresas abriram capital no Brasil. A amostra do presente trabalho foi reduzida a 98 empresas devido à exclusão das empresas que se encaixam nos seguintes critérios:

a) Empresas do setor "Finanças e Seguros", "Fundos" e "Administração de empresas e empreendimentos", devido às peculiaridades de suas operações e informações contábeis.

b) Empresas que abriram e fecharam capital no período 2002-2010,

c) Empresas que emitiram Brazilians Deposit Receipts (BDRs).

Além disso, como um dos propósitos deste trabalho é determinar os fatores que influenciam a decisão de abertura de capital, seria necessário restringirmos a base a empresas cujo IPO fosse plausível. De acordo com Pagano et al. (1998), na Itália era necessário que uma companhia possuísse patrimônio líquido superior a 10 bilhões de liras e lucros positivos nos três anos anteriores à listagem. Já na França, de acordo com Chaouani (2010), é necessário patrimônio líquido e ativo total superiores a 1,5 e 3,0

\footnotetext{
${ }^{11}$ Os resultados dessa averiguação são apresentados na tabela A1 no apêndice.
} 
milhões de euros, respectivamente. No Brasil não existe tal tipo de imposição, então a restrição no banco de dados não foi necessária. ${ }^{12}$

A tabela 1 abaixo mostra a distribuição dos IPOs ao longo dos anos. Pode-se observar que a amostra cobre grande parte da população, com um total de $73,7 \%$ das companhias que abriram capital no período de análise. Além disso, nota-se grande concentração no número de IPOs no hot market, que compreende os anos de 2006 e 2007. Esse clustering temporal dos IPOs também é observado nos EUA (Ritter, 1984) e em outros países (Loughran et al., 1994 e Pagano et al., 1998).

Tabela 1 - Distribuição dos IPOs ao longo dos anos

\begin{tabular}{|c|c|c|}
\hline $\begin{array}{c}\text { Ano de } \\
\text { Abertura }\end{array}$ & $\begin{array}{c}\text { Todos IPOs na } \\
\text { Bovespa }\end{array}$ & $\begin{array}{c}\text { Número de } \\
\text { IPOs na } \\
\text { Amostra }\end{array}$ \\
\hline 2002 & 4 & $3(75,0 \%)$ \\
2003 & 2 & $2(100,0 \%)$ \\
2004 & 7 & $6(85,7 \%)$ \\
2005 & 9 & $7(77,8 \%)$ \\
2006 & 26 & $20(76,9 \%)$ \\
2007 & 64 & $43(67,2 \%)$ \\
2008 & 4 & $4(100,0 \%)$ \\
2009 & 6 & $3(50,0 \%)$ \\
2010 & 11 & $10(90,9 \%)$ \\
\hline Total & $\mathbf{1 3 3}$ & $\mathbf{9 8}(\mathbf{7 3 , 7 \%})$ \\
\hline
\end{tabular}

Fonte: Economática.

Por sua vez, a base de empresas de capital fechado tem como fonte o banco de dados da revista MM. Além de empresas não listadas na BM\&FBovespa, essa base contém também companhias de capital aberto, o que nos obrigou a identificar as empresas que eram listadas na Bovespa para posteriormente excluí-las.

Como as classificações dos setores das companhias na Economática e na MM são distintas, reagrupamos as empresas sob um mesmo critério. Como a Economática possui 26 setores e a MM, 22, optamos por utilizar os setores da MM como referência. A tabela 2 mostra o resultado final do agrupamento das empresas por setor no período 2002-2010.

\footnotetext{
${ }^{12}$ Foram consultados underwitters e a CVM sobre eventuais pré-requisitos contábeis para emissão primária de ações.
} 
Tabela 2 - Distribuição dos setores em 2002-2010

\begin{tabular}{|l|c|c|c|c|}
\hline Setor & IPOs & $\mathbf{\%}$ & Não-IPOs & $\mathbf{\%}$ \\
\hline Autoindústria & 2 & 2,0 & 29 & 4,0 \\
Bens de Capital & 1 & 1,0 & 10 & 1,4 \\
Bens de Consumo & 7 & 7,1 & 72 & 9,9 \\
Comércio & 7 & 7,1 & 42 & 5,8 \\
Comunicações & 0 & 0,0 & 122 & 16,8 \\
Diversos & 0 & 0,0 & 7 & 1,0 \\
Eletroeletrônico & 2 & 2,0 & 35 & 4,8 \\
Energia & 6 & 6,1 & 77 & 10,6 \\
Indústria Digital & 3 & 3,1 & 11 & 1,5 \\
Indústria da Construção & 18 & 18,4 & 47 & 6,5 \\
Mineração & 1 & 1,0 & 21 & 2,9 \\
Papel e Celulose & 2 & 2,0 & 13 & 1,8 \\
Produção Agropecuária & 5 & 5,1 & 33 & 4,6 \\
Química e Petroquímica & 5 & 5,1 & 69 & 9,5 \\
Serviços & 21 & 21,4 & 54 & 7,4 \\
Siderurgia e Metalurgia & 1 & 1,0 & 56 & 7,7 \\
Transporte & 13 & 13,3 & 21 & 2,9 \\
Têxteis & 4 & 4,1 & 7 & 1,0 \\
\hline Total & $\mathbf{9 8}$ & $\mathbf{1 0 0}$ & $\mathbf{7 2 6}$ & $\mathbf{1 0 0}$ \\
\hline
\end{tabular}

Fonte: Economática e Maiores \& Melhores.

Das empresas que abriram capital, nota-se uma concentração nos setores de "Serviços", "Indústria de Construção" e "Transporte". Por outro lado, as de capital fechado concentram-se em "Comunicações", "Energia" e "Bens de Consumo". Observa-se discrepância entre os setores das companhias listadas e não-listadas, em especial para comunicações, segmento com 122 empresas fechadas e nenhuma nova listagem na BM\&FBovespa no período de análise.

\subsection{Definição das variáveis para os fatores ex-ante}

Para reduzir a interferência de outliers na estimação dos resultados, excluímos da base de dados os valores do percentil abaixo de $1 \%$ e acima de $99 \%$. Deflacionamos os valores pelo IPCA (Índice de Preços do Consumidor Amplo) utilizando como base o ano de 2010. As seguintes variáveis foram empregadas para estimar os determinantes da abertura de capital:

a) o logaritmo natural da receita operacional da empresa i no ano t-1 como proxy para tamanho:. 
Tamanho $_{i t}=\ln ($ Receita Operacional Bruta $i t-1)$

b) a taxa de crescimento da Receita Operacional Bruta (Rob) da empresa i no ano t como proxy de crescimento:

Crescimento $_{i t}=\frac{\left(\text { Rob }_{i t}-\text { Rob }_{i t-1}\right)}{\text { Rob }_{i t-1}}$

c) Roa: Retorno sobre Ativos é dada pela relação entre Lucros Antes de Juros, Impostos, Depreciação e Amortização (Ebitda - Earnings Before Interest, Taxes, Depreciation and Amortization) e Ativo Total (At) em t-1, conforme a equação 11.

$\operatorname{Roa}_{i t}=\frac{E b i t d a_{i t-1}}{A t_{i t-1}}$

d) Alavancagem: definida pela equação 12, em que Pc é o Passivo Circulante, Elp é o Exigível de Longo Prazo e Pl é o Patrimônio Líquido da empresa.

Alavancagem $_{i t}=\frac{\left(P c_{i t-1}+E l p_{i t-1}\right)}{\left(P c_{i t-1}+E l p_{i t-1}+P l_{i t-1}\right)}$

f) Capex: expressa a relação entre aquisição de capital físico, dada pela variação do Imobilizado Líquido (Imobliq).

Capex $_{i t}=$ Imobliq $_{i t}-$ Imobliq $_{i t-1}$

e) MTB: mediana do q de Tobin do setor $\mathrm{j}$ no ano $\mathrm{t}$, abrangendo as $\mathrm{i}$ empresas listadas na BM\&FBovespa que compõe o setor $\mathrm{j}$ no ano $\mathrm{t}$, calculada com base nos dados da Economatica, de acordo com a equação 14. O termo VM representa o valor de mercado das empresas, os termos Pcirc e Pncirc são, respectivamente, o Passivo Circulante e o Passivo Não Circulante, o termo Est refere-se aos estoques da empresa, Atcirc é o Ativo Circulante e At é o Ativo Total. Calculada a mediana do q de Tobin de cada setor j para cada ano t, os valores foram imputados para cada empresa i candidata a fazer uma IPO, em cada ano t. Cabe enfatizar que para o cálculo desta variável foram utilizadas todas as empresas listadas na BM\&FBovespa, e não apenas as que abriram capital no período de análise. 


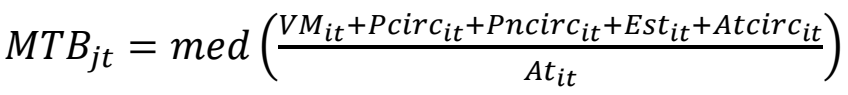

\subsection{Definição das variáveis para as consequências ex-post}

Com base na literatura, utilizamos como proxies de performance operacional o retorno sobre ativos, retorno nas vendas e retorno nos lucros; como medida de eficiência utilizamos asset turnover; a razão dívida sobre ativo foi utilizada para mensurar alavancagem; e como medida de investimento, a proxy foi o Capex normalizado pelo total de ativos (ver tabela 3 ).

Tabela 3 - Definição das variáveis de performance

\begin{tabular}{|l|l|}
\hline Variável & Definição \\
\hline Proxies para lucratividade \\
\hline ROA & Retorno operacional sobre ativos: EBITDA dividido por ativo total \\
RSV & Retorno operacional sobre vendas: EBITDA dividido por receita total \\
ROE & Retorno operacional sobre lucros: Lucro Líquido dividido por ativo total \\
\hline Proxy para eficiência & Asset turnover: Receita total dividida por ativo total \\
\hline GIRO & Razão dívida por ativo: Dívida total bruta dividido por ativo total \\
\hline Proxy para alavancagem \\
\hline DEBT & Investimento em bens de capital dividido por ativo total \\
\hline Proxy para investimento \\
\hline CAPEX
\end{tabular}

\subsection{Estatísticas descritivas e correlograma}

A tabela A2, apresentada no apêndice, fornece as estatísticas descritivas e o número de observações das variáveis financeiras relevantes. O painel A mostra os dados das empresas listadas na BM\&FBovespa, enquanto o painel B reporta os dados das empresas fechadas que potencialmente poderiam vir a realizar um IPO.

Uma breve inspeção das tabelas revela que as empresas que realizaram IPO apresentam valores mais elevados nas variáveis Ativo Total, Lucro Líquido, Ebitda, Capex e Crescimento. Por sua vez, as empresas fechadas são as que possuem maior Receita Total, Tamanho e Roa. As maiores diferenças entre os dados encontram-se na variável 
Capex e Lucro Líquido, que são bastante superiores nas empresas que fizeram IPO, e na variável Receita Total, superior para as empresas de capital fechado.

Verificamos, também, a correlação entre as variáveis explicativas utilizadas nos modelos. De acordo com a tabela A3, nota-se que a correlação entre as variáveis é próxima de zero na maioria dos casos. 


\section{RESULTADOS}

\subsection{Fatores determinantes da decisão de realizar IPO}

Nesta sessão, utilizamos modelos logit para estimar a probabilidade de uma empresa abrir o capital. A variável dependente $I P O_{i t}$ assume valor 0 se a firma $i$ permanece fechada no período $t$ e valor 1 se ela realiza o IPO. As equações dos modelos estimados são:

$\operatorname{Pr}\left(\right.$ IPO $\left._{i t}=1\right)=F\left(\beta_{0}+\beta_{1}\right.$ TAMANHO $_{i t-1}+\beta_{2}$ CAPEX $_{i t}+\beta_{3}$ CRESCIMENTO $_{i t}+$

$\left.\beta_{4} R O A_{i t-1}+\beta_{5} A L A V A N C A G E M_{i t-1}+\beta_{6} M_{T H} B_{i t}\right)$

$\operatorname{Pr}\left(I_{P O}=1\right)=F\left(\beta_{0}+\beta_{1}\right.$ TAMANHO $_{i t-1}+\beta_{2}$ CAPEX $_{i t}+\beta_{3}$ CRESCIMENTO $_{i t}+$

$\beta_{4} R_{i t-1}+\beta_{5} A_{\text {ALAVANCAGEM }}{ }_{i t-1}+\beta_{6}$ MTB $\left._{i t}+\sum_{t=2003}^{2009} \beta_{t} A N O_{t}\right)$

em que $F\left(\right.$.) é a distribuição logística e $A N O_{t}$ é a dummy de calendário anual. Excluímos da amostra empresas após terem feito o IPO, outliers pertencentes ao quantil abaixo de $1 \%$ e superior a 99\%, e empresas com patrimônio líquido negativo e com a variável crescimento abaixo de $-100 \%$ e superior a $100 \%$.

A tabela 4 apresenta os resultados das estimações. Nota-se que a única diferença entre os modelos ocorre com as variáveis dummy de ano. Além dos coeficientes, estão também reportados os odds ratios e os efeitos marginais de cada variável.

Os resultados do primeiro modelo sugerem que empresas menores, com elevado crescimento, de maior rentabilidade, com maiores taxas de investimentos e de endividamento apresentaram maior probabilidade de abrir o capital. A probabilidade também se correlaciona positivamente com a mediana do valuation das empresas já listadas no setor em que a empresa da amostra opera. Todos os coeficientes são significativos a $1 \%$, exceto o da variável MTB, significativa a $5 \%$. Como esperado, os sinais dos parâmetros do segundo modelo são os mesmos do primeiro, porém a variável MTB deixa de ser estatisticamente significante. Apenas as dummies de ano de 2008 e 2009 são significativas, indicando que naquele período a probabilidade de abertura de capital era menor, fato justificado pela crise financeira de então. 
Tabela 4 - Modelos logit de determinação ex-ante de IPO em 2002-2010

\begin{tabular}{|c|c|c|c|c|c|c|}
\hline & \multicolumn{3}{|c|}{ Modelo 1} & \multicolumn{3}{|c|}{ Modelo 2} \\
\hline Variáveis & Coeficientes & Odds $^{1}$ & $d y / d x$ & Coeficientes & Odds ${ }^{1}$ & $d y / d x$ \\
\hline Constante & $12,29 * * *$ & & & $13,90 * * *$ & & \\
\hline Tamanho & $-1,432 * * *$ & 0,2389 & $-0,0159$ & $-1,445^{* * *}$ & 0,2358 & $-0,0120$ \\
\hline Crescimento & $2,051 * * *$ & 7,7778 & 0,0227 & $2,057 * * *$ & 7,8262 & 0,0171 \\
\hline ROA & $3,525 * * *$ & 33,9567 & 0,0391 & $3,685 * * *$ & 39,8472 & 0,0306 \\
\hline CAPEX & $2,56 \mathrm{E}-06 * * *$ & 1,0000 & $2,84 \mathrm{E}-08$ & $2,92 \mathrm{E}-06 * * *$ & 1,0000 & $2,42 \mathrm{E}-08$ \\
\hline Alavancagem & $2,076 * * *$ & 7,9722 & 0,0230 & $2,132 * * *$ & 8,4357 & 0,0177 \\
\hline MTB & $0,674 * *$ & 1,9612 & 0,0075 & 0,135 & 1,1449 & 0,0011 \\
\hline d2004 & & & & $-0,636$ & 0,5296 & $-0,0043$ \\
\hline d2005 & & & & $-0,759$ & 0,4681 & $-0,0049$ \\
\hline d2006 & & & & 0,198 & 1,2192 & 0,0018 \\
\hline d2007 & & & & 0,0935 & 1,0980 & 0,0008 \\
\hline d2008 & & & & $-1,908 * *$ & 0,1484 & $-0,0093$ \\
\hline d2009 & & & & $-2,273^{*}$ & 0,1030 & $-0,0101$ \\
\hline Observações & \multicolumn{3}{|c|}{1,500} & \multicolumn{3}{|c|}{1,500} \\
\hline IPO=1 & \multicolumn{3}{|c|}{98} & \multicolumn{3}{|c|}{98} \\
\hline IPO=0 & \multicolumn{3}{|c|}{1402} & \multicolumn{3}{|c|}{1402} \\
\hline Log likelihood & \multicolumn{3}{|c|}{-149.7} & \multicolumn{3}{|c|}{-142.9} \\
\hline Chi-quadrado & \multirow{2}{*}{\multicolumn{3}{|c|}{104.8}} & \multicolumn{3}{|c|}{118.4} \\
\hline Pseudo R2 & & & & \multicolumn{3}{|c|}{0.293} \\
\hline
\end{tabular}

${ }^{1}$ Odds ratio representam o aumento na probabilidade de realização de IPO em relação a probabilidade de manter-se privada quando a variável dummy muda de 0 para 1.

$* * * \mathrm{p}<0.01, * * \mathrm{p}<0.05, * \mathrm{p}<0.1$.

Fonte: Elaboração própria.

Como apontado por Pagano et al. (1998), o sinal positivo da variável MTB pode ter duas interpretações. Uma possibilidade é que os empresários queiram explorar o timing de sobrevalorização das empresas já listadas do mesmo setor no mercado de ações. A hipótese alternativa é que o elevado MTB reflete o valor presente de futuras oportunidades de crescimento do setor, o que demandaria investimentos e recursos para financiá-los. Para discriminar entre essas hipóteses, torna-se necessário examinar os efeitos ex-post do IPO sobre o volume de investimento: se for maior nas empresas que realizaram IPOs vis-à-vis as empresas que permaneceram fechadas, é uma evidência em favor da segunda hipótese; caso contrário, é mais provável que market-timing tenha ocorrido.

O coeficiente da variável rentabilidade apresentou sinal positivo, sugerindo que os empresários escolhem o timing do IPO quando as empresas têm uma lucratividade elevada, seja esta efetiva ou obtida via window dressing. Em ambos os casos, haveria expectativa de reversão à média da taxa de retorno (Degeorge e Zeckhauser, 1993). 
A variável tamanho mostrou-se estatisticamente significante e com sinal negativo, ${ }^{13}$ resultado em acordo com Chaouani (2010), que analisa IPOs na França, e em desacordo com Pagano et al. (1998) e Aldrighi et al. (2009), referentes a amostras de empresas, respectivamente, da Itália e do Brasil. Cabe notar que, no período analisado, em especial em 2006 e 2007, diversas empresas pré-operacionais (com poucos ativos antes da emissão) e empresas com baixo valor patrimonial (como construtoras e imobiliárias, que representam parcela considerável da amostra de IPOs) optaram pela realização de IPO. $^{14}$

A variável investimento em máquinas e equipamentos mostrou-se significante e positivamente correlacionada com a probabilidade de ocorrência de um IPO. Tal evidência em conjunto com os sinais positivos e as altas significâncias estatísticas do nível de alavancagem, do MTB e do crescimento das vendas pode sugerir restrição de crédito (ver Brau, 2010). É possível que, antes do IPO, as empresas se endividaram muito para financiar investimentos e, diante do rápido crescimento e expectativas promissoras de oportunidades do setor, restava-lhes apenas a captação de fundos via IPOs. ${ }^{15}$.

\subsection{Efeitos ex-post dos IPOs}

No gráfico 1 apresentamos a evolução das medianas das variáveis de performance operacional (definidas no capítulo 4). Adotamos uma janela temporal de seis anos: além do ano em que as empresas fizeram o IPO (tomado como referência, $t=0$ ), consideramos dois anos antes e três anos depois do IPO.

\footnotetext{
13 A utilização de outra proxy para tamanho usualmente empregada na literatura, o ativo total, não modifica os resultados das nossas estimações.

${ }^{14} \mathrm{O}$ porte pequeno pode estar correlacionado com a idade das empresas, indicando que as que optaram por realizar IPO eram mais novas - como ocorre nos EUA (Mikkelson et al., 1997) e em contrGIROe com a Itália (Pagano et al, 1998). Não dispondo dessa variável, não pudemos testar essa hipótese.

15 A atividade de venture capital e private equity é muita restrita no Brasil, mobilizando recursos cujo montante, embora em rápido crescimento - passou de 0,6\% do PIB em 2004 para 1,7\% em 30 de junho de 2008 -, ainda é bastante inferior à média mundial de 3,7\% (Ferrari e Minardi, 2010).
} 
Painel A: ROA

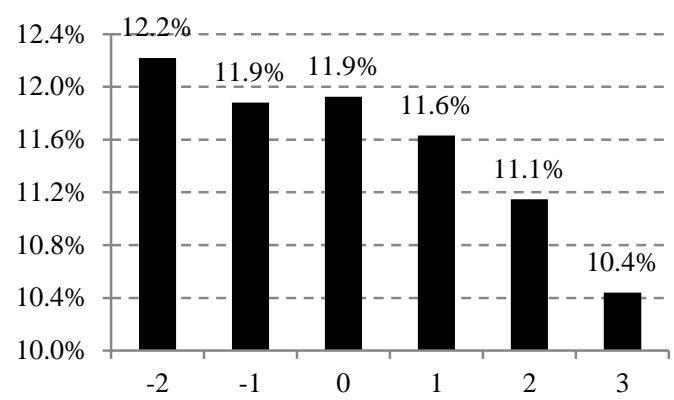

Painel C: ROE

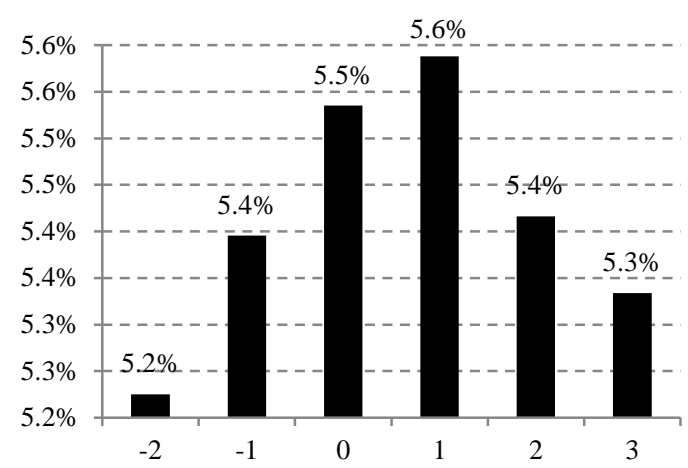

Painel E: CAPEX

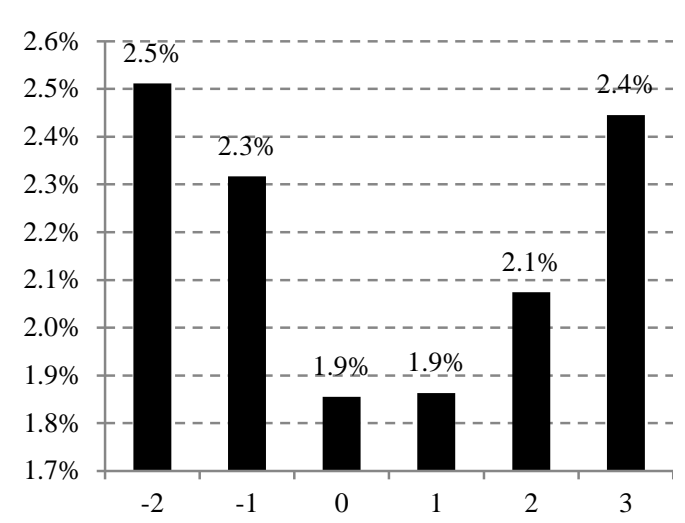

Painel B: RSV

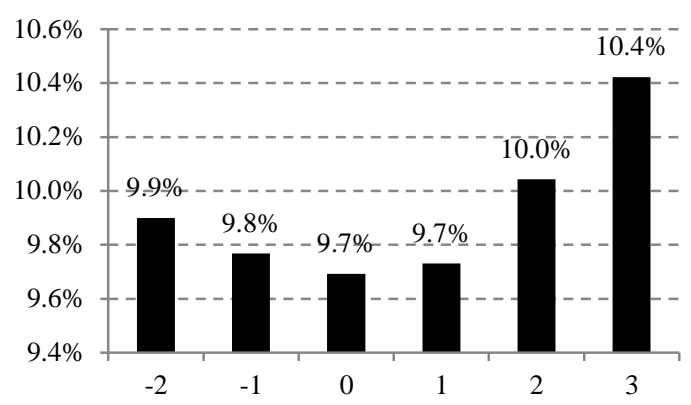

Painel D: GIRO

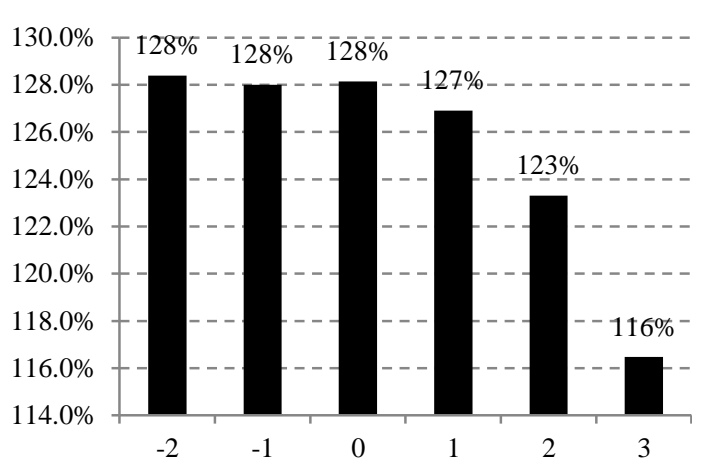

Painel F: DEBT

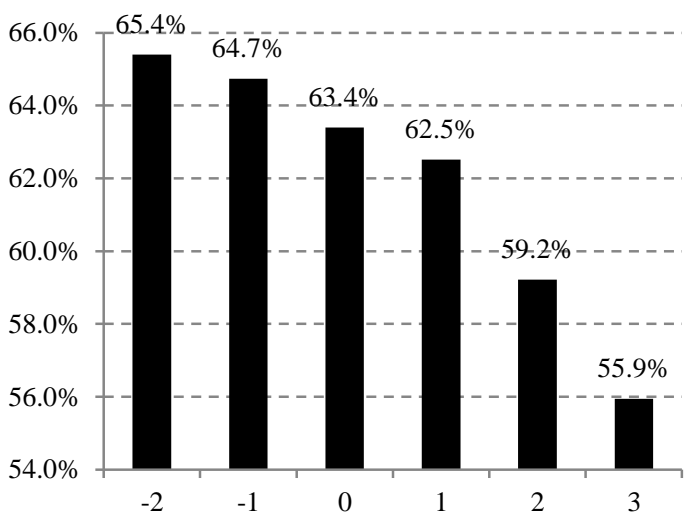

\section{Gráfico 1- Desempenho operacional dos IPOs realizados em 2004-2007}

Fonte: Elaboração própria mediante utilização de dados da Economática.

Há forte discrepância nas medidas de rentabilidade: queda monotônica do ROA (variável mais utilizada na literatura), queda e recuperação após o IPO do OROS, e crescimento até o primeiro ano após o IPO e depois queda do OROP. A proxy para eficiência mostra estabilidade até o IPO, após o qual declina. Os investimentos apresentam trajetória declinante, revertida a partir do segundo ano após o IPO. A alavancagem registra queda monotônica no período. 


\subsection{Análise de desempenho segundo a metodologia do propensity score matching}

As medianas das variáveis de desempenho podem refletir também a influência do ciclo econômico e de choques exógenos, como mudanças regulatórias ou tecnológicas. Assim, como controle para avaliar a performance operacional das empresas pós-IPO, comparamo-as com outras empresas semelhantes que não abriram o capital por meio do PSM.

O primeiro passo no PSM é a especificação do modelo. Nesta investigação, estimamos o modelo logit, apresentado na tabela $6,{ }^{16}$ para identificar os fatores que afetam a decisão de IPO - nosso propensity score. Feito isso, procedemos ao balanceamento das variáveis ex-ante no modelo escolhido. O painel A da tabela A4 (apêndice) revela pelos testes t que as covariadas estão bem balanceadas e que o balanceamento entre os grupos de controle e tratamento geram uma redução substancial no viés, principalmente para as variáveis Tamanho, Crescimento, ROA e Capex. Portanto, o matching é mais adequado do que a amostra não-pareada para os testes de impacto.

A etapa seguinte do teste de balanceamento consiste em reestimar o propensity score da amostra pareada e comparar o pseudo- $\mathrm{R}^{2}$ antes e depois de efetuado o pareamento. $\mathrm{O}$ pseudo- $\mathrm{R}^{2}$ expressa o poder dos regressores de explicar a probabilidade de uma empresa realizar o IPO. Feito o matching, não deveria haver diferenças sistemáticas entre os dois grupos, e portanto o pseudo- $\mathrm{R}^{2}$ teria de ser baixo. De fato, o painel B da tabela A4 mostra que o pseudo- $\mathrm{R}^{2}$ cai de 0,337 para 0,036 , o que fornece segurança às estimativas.

Como destacado no capítulo 3, o emprego do PSM pressupõe independência das variáveis. Dado o caráter dinâmico (utilização de série de tempo) deste estudo, tal hipótese pode ser violada - por exemplo, a observação sobre o nível de investimento de uma dada empresa em 2007 pode não ser independente do que fora observado em 2006. Assim, além de efetuarmos o matching para todo o período, fizemos o pareamento para cada ano individual entre 2004 e 2007.

Calculou-se o ATT com o intuito de mensurar a diferença de performances entre uma empresa que realizou IPO e outra que se manteve com o capital fechado com

\footnotetext{
${ }^{16}$ No que segue, empregamos a especificação referente ao modelo 1, por ter se mostrada estatisticamente mais significativa.
} 
características econômicas-financeiras similares. Devido à maior representatividade, a base utilizada restringiu-se nessa etapa às empresas que realizaram IPO no período 2004-2007. Cabe ressaltar que os erros-padrão foram calculados através da técnica de bootstrap utilizando 200 repetições - que é o padrão da literatura. As análises basearamse em três indicadores: a magnitude das estimações do ATT, o sinal desses coeficientes, e os valores-t gerados pelo algoritmo de bootstrap para verificação da significância estatística das estimações.

Inicialmente, foram realizadas estimações separadas para os anos de 2004, 2005, 2006 e 2007, observando-se a performance nos três anos posteriores à abertura de capital. ${ }^{17}$ Feito isso para os quatro anos em questão, realizamos estimações para a base completa, que agrega os IPOs realizados no período 2004-2007, observando a performance ex-post para os anos de 2008, 2009 e 2010.

Os resultados do Average Treatment Effect, estimado pela diferença entre os grupos tratados (IPOs) e não-tratados (Não-IPOs), são apresentados no apêndice. Para as empresas que abriram capital em 2004, as estimativas de ATT das três medidas de performance (retorno operacional dos ativos, retorno operacional das vendas e retorno operacional dos lucros) são distintas (tabela A5): a primeira medida apresenta resultado inferior, superior e inferior ao das empresas que mantiveram seu capital fechado nos anos $+1,+2$ e +3 , respectivamente. O retorno operacional das vendas foi superior para as empresas que fizeram IPOs em todos os anos, enquanto o retorno operacional do lucro foi sempre inferior. Entretanto, nenhum desses resultados foram estatististicamente significantes. Os erros-padrão calculados mediante bootstrap resultaram em estatísticas t que não foram significantes nem a 10\%, o que indica que não há diferença de rentabilidade entre os IPOs feitos em 2004 e as empresas com capital fechado com características semelhantes nesse período de análise.

Para o mesmo ano, observamos que os IPOs apresentam queda de eficiência e alavancagem e aumento do investimento em capital fixo. Todavia, as estimativas de erros-padrão calculadas via bootstrap também não mostraram significância estatística,

\footnotetext{
${ }^{17}$ Por exemplo, para a base de 2006, as empresas de capital aberto são compostas apenas pelos IPOs realizados em 2006, e o desempenho observado em t+1, t+2 e t+3 refere-se a 2007, 2008 e 2009, respectivamente.
} 
indicando inexistência de diferença entre essas medidas de desempenho para os IPOs realizados em 2004.

Para 2005, 2006 e 2007, não há tendência nas estimações de ATT das variáveis de rentabilidade (ver tabelas A6, A7 e A8). Por exemplo, os IPOs realizados em 2006 apresentaram retorno operacional das vendas superiores aos não-IPOs nos três anos posteriores, enquanto observa-se o contrário para os IPOs de 2007. Novamente, não há significância para os resultados de rentabilidade para estes três anos.

Em todos os períodos de análise, as medidas de rotatividade dos ativos, grau de endividamento e investimento em capital fixo mantiveram o mesmo padrão: as empresas que lançaram IPOs reduziram a rotatividade dos ativos e a alavancagem e aumentaram os investimentos em capital fixo, embora os resultados sigam sem significância estatística.

Uma possível explicação para essa recorrente falta de significância estatística é o baixo volume de IPOs realizados em cada ano individualmente. A metodologia de PSM é frequentemente descrita como data hungry method (método faminto por dados) devido às elevadas exigências que impõe sobre o banco de dados (Henrich et al., 2010). Para contornar esse problema, calculamos o PSM para toda a base de IPOs no período 20042007 (Tabela A9).

Para quaisquer das medidas de retorno, não há diferença estatística entre os IPOs e os não-IPOs no período de quatro anos - como observado para cada ano individual. Como esperado, o ATT da rotatividade dos ativos e grau de endividamento apresentou sinal negativo e o ATT do investimento em capital fixo sinal positivo. Mas agora a variável investimento revelou significância estatística ao nível de $10 \%$ para 2009 e a 5\% para 2010.

Devido à possível influência do algoritmo Kernel nesses resultados, é necessário efetuar um teste de robustez para mostrar que as estimativas encontradas não dependem da metodologia escolhida. Para isso, calculamos os ATTs e seus respectivos erros-padrão por bootstrap com 200 repetições dos demais algoritmos: 
i) Nearest Neighbor utilizando 1 nearest neighbor;

ii) Nearest Neighbor utilizando 5 nearest neighbors;

iii) Caliper matching utilizando caliper de 0,001;

iv) Radius matching utilizando caliper de 0,001 ;

v) Local linear regression.

Semelhantemente ao Kernel Matching, o ATT calculado com todos os outros algoritmos para os anos de maneira individual não mostraram significância estatística nos resultados mediante a estimação dos erros-padrão via bootstrap. ${ }^{18} \mathrm{~A}$ base agregada de 2004-2007 evidenciou novamente apenas o investimento em capital fixo significante. Como esperado, o coeficiente foi positivo em todos os algoritmos utilizados, mas a significância altera-se de acordo com o método utilizado. Para evidenciar essas diferenças, os resultados referentes à estimação do ATT dessa variável com os seis algoritmos de PSM distintos seguem reportados na tabela A10 do apêndice.

De maneira similar ao método Kernel descrito acima, todos os outros algoritmos mostraram significância referente ao desempenho superior dos IPOs em 2009 e 2010 para o investimento em capital fixo. Pela tabela A10 observa-se que a significância do investimento para 2008 foi verificada em dois dos seis algoritmos - no Nearest Neighbour 1 e 5. Para os demais anos, a significância varia conforme muda a metodologia, mas os dados apontam para o mesmo resultado: empresas que realizaram IPO tiveram investimento superior às que permanceram fechadas. Essa foi a única variável de performance que mostrou-se relevante estatisticamente em todos os períodos de análise mediante todos os métodos de estimação empregados.

Sendo assim, através da base utilizada para esta dissertação, ao contrário do que a literatura internacional sugere, os resultados da economia brasileira para os IPOs realizados em 2004, 2005, 2006 e 2007 não indicam diferença estatisticamente significante de rentabilidade nos anos posteriores à abertura de capital entre IPOs e nãoIPOs. Assim, na média, não há ganhos ou perdas de rentabilidade financeira a uma empresa que realiza IPO. Além disso, elas não se tornam mais ou menos eficientes, ao mesmo tempo em que o nível de alavancagem não aparentou diferenças entre os dois tipos de empresas, o que implica que, na média, não se observou o fenômeno de reestruturação financeira nos IPOs analisados.

\footnotetext{
${ }^{18}$ Como os resultados foram similares, não os reportamos no trabalho.
} 
Com os resultados referentes ao investimento ex-post, podemos confrontar as hipóteses sobre a opção dos gestores de abrir capital quando as empresas do setor em que estão inseridas estão sobrevalorizadas. Como os IPOs apresentaram crescimento do investimento estatisticamente significante acima das empresas fechadas, é provável que tenham sido realizados devido às expectativas favoráveis de crescimento futuro do setor no qual operam. De acordo com os prospectos de ofertas públicas da maioria das empresas, os recursos da emissão seriam empregados para financiar a expansão, possivelmente como alternativa às restrições no crédito. Tal relato é compatível com o fato de piora nas medidas de rentabilidade. 


\section{CONCLUSÕES}

Esta dissertação buscou investigar os fatores que afetaram a decisão de algumas empresas brasileiras de realizar um IPO no período 2002-2007 bem como as implicações ex post para algumas variáveis (lucratividade, endividamento, crescimento e investimento). Por meio de um banco de dados único composto de empresas com capital aberto e fechado, estimamos um modelo logit cujos resultados sugerem que as empresas menores, mais lucrativas e alavancadas, que mais investiram e cresceram e que, ademais, aproveitaram o período de preços elevados de ações das empresas já listadas operando nos setores correspondentes apresentavam uma maior probabilidade de abrir o capital.

Por meio da metodologia do propensity score matching, estimamos a diferença média nas medidas de rentabilidade, eficiência e alavancagem entre empresas que realizaram IPO e as que permaneceram com o capital fechado nos anos posteriores ao IPO. Usando o algoritmo de bootstrap, apenas a variável investimento em capital fixo se mostrou significativa, sendo superior para as empresas que lançaram IPO. Como a probabilidade de realizar um IPO é positivamente relacionada com o valor acionário das empresas do mesmo setor, essa evidência de investimentos relativamente mais elevados das empresas após o IPO pode sugerir que a abertura de capital associa-se com a captação de recursos visando ao funding de boas oportunidades de investimentos futuros. 


\section{REFERÊNCIAS}

ALDRIGH, D. M., AFONSO, E. A., CAPPARELli, G. \& SANTOS, A. As ofertas públicas iniciais na Bovespa no período recente: Características das empresas, estrutura de propriedade e de controle, e desempenho. ANPEC, 2009.

BRAU, J. Why Firms Go Public? Forthcoming in the Oxford Handbook of Entrepreneurial Finance. 2010.

BOSSOLANI, T. IPO e o Desempenho das Empresas. Dissertação (Mestrado em Finanças e Economia Empresarial) - Escola de Economia de São Paulo, Fundação Getúlio Vargas. São Paulo, 2009.

CAI, J. \& WEI, K. The Investment and Operating Performance of Japanese IPO. Pacific-Basin Finance Journal 5, 389-417. 1997.

CALIENDO, M. \& KOPEINIG, S. Some practical guidance for the implementation of propensity score matching. Institute for the Study of Labor, Discussion paper 1588, 129. 2005.

CELIKYURT, U., SEVILIR, M. \& SHIVDASANI, A. Going Public to Acquire? The Acquisition Motive in IPOs. Journal of Financial Economics 96, 345-363. 2010.

CHAOUANI, S., Using propensity score matching and estimating treatment effects: an application to the post-issue operating performance of French IPOs, International Research Journal of Finance and Economics 48, 73-93. 2010.

DEGEORGE, F. \& ZECKHAUSER, R. The reverse $L B O$ decision and firm performance: Theory and evidence. Journal of Finance, 48, 1323 - 1348. 1993.

FERRARI, G. \& MINARDI, A. O Desempenho de Ofertas Públicas Inicias de Empresas Brasileiras Financiadas por Fundos de Private Equity. Insper Working Paper, WPE 224. 2010 
GUO, S. \& FRASER, M. Propensity Score Analysis: Statistical Methods and Applications. Sage Publications, Inc. 2009.

HECKMAN, J.J. \& ROBB, R. Alternative Methods for Evaluating the Impact of Interventions: An Overview. Journal of Econometrics 30, 239-267. 1985.

HEINRICH, C., MAFFIOLI, A. \& VÁZQUEZ, G. A primer for applying propensityscore matching. Inter-American Development Bank, 1-54. 2010.

JAIN, B. \& KINI, O., The post-issue operating performance of IPO firms, Journal of Finance 49, 1999-1726. 1994.

JENSEN, M. \& MECKLING, W. 1976. Theory of the Firm, Managerial Behavior, Agency Costs and Ownership Structure, Journal of Financial Economics 3, 305-360. 1976.

KHURSHED, A., PALEARI, S., \& VISMARA, S., The Operating Performance of Initial Public Offerings: the UK experience. Unpublished working paper, University of Manchester. 2003.

KORAJCZYK, R., LUCAS, D. \& MCDONALD, R. Understanding stock price behavior around the time of equity issues, in R. Glenn Hubbard, Ed.: Asymmetric Information, Corporate Finance, and Investment (University of Chicago Press, Chicago). 1990.

LOUGHRAN, T. \& RITTER, J. Why Has IPO Underpricing Increased Over Time?, Financial Management, 33, 5-37. 2004.

LOUGHRAN, T. \& RITTER, J. (a) The New Issue Puzzle, Journal of Finance 50, 2349. 1995.

LOUGHRAN, T. \& RITTER, J. (b) The Operating Performance of Firms Conducting Seasoned Equity Offerings, Journal of Finance 52, 1823-1850. 1995. 
LOUGHRAN, T., RITTER, J. \& RYDQVIST. Initial Public Offerings: International Insights. Pacific-Basin Finance Journal 2, 165-199. 1994.

MIKKELSON, W., PARTCH, M., \& SHAH, K., Ownership and operating performance of companies that go public. Journal of Financial Economics 44, 281-307. 1997.

MYERS, S. The Capital Structure Puzzle, Journal of Finance, 39, 575-592. 1984.

PAGANO, M., PANETTA, F. \& ZINGALES, L., Why do Companies Go Public? An Empirical Analysis, Journal of Finance 53(1), 27-64. 1998.

RITTER, J. The Hot Issue Market of 1980. Journal of Business, 32, 215-240. 1984.

ROSENBAUM, P.R. \& RUBIN, D. B. The Central Role of the Propensity Score in Observational Studies for Causal Effects. Biometrika, 70(1), 41-55. 1983

SCHIOZER, R., OLIVEIRA, R. F. \& SAITO, R. Why do Banks go Public? Evidence from the 2005-2007 wave of Brazilian Bank IPOs. Central Bank of Brazil working paper. 2010.

WOOLDRIDGE, J. Econometric Analysis of Cross Section and Panel Data. The MIT Press, 2002. 


\section{APÊNDICE}

Tabela A1 - Mudanças nos IPOs realizados em 2002-2010

\begin{tabular}{|l|l|}
\hline Empresa & Mudança \\
\hline Abyara & Cancelada \\
Ecodiesel & V-Agro \\
GVT Holding & Cancelada \\
Inpar & Viver \\
Tenda & Cancelada \\
Guarani & Cancelada \\
Julio Simões & JSL \\
Tivit & Cancelada \\
Visanet & Cielo \\
Nossa Caixa & Cancelada \\
Terna & Taesa \\
Brascan & Brookfield \\
Datasul & Cancelada \\
Abnote & Valid \\
Company & Cancelada \\
Vivax & Cancelada \\
SEB & Cancelada \\
Satipel & Fusão com Duratex \\
Invest Tur & BHG \\
Agra Incorp & Cancelada \\
\hline
\end{tabular}

Diversas empresas que constavam no site http://www.bmfbovespa.com.br/cias-listadas/consultas/iposrecentes/ipos-recentes.aspx?idioma=pt-br não estavam presentes em nosso banco de dados. O motivo foi de cancelamento das ações na Bovespa, fusão com outra empresa ou mudança de nome. A tabela evidencia o motivo da ausência de dados e as medidas efetuadas para corrigir este problema. 
Tabela A2 - Análise descritiva das variáveis selecionadas, 2002-2010

\begin{tabular}{|l|c|c|c|c|c|c|}
\hline Painel A: Empresas que realizaram IPO \\
\hline Variável & Observações & Mediana & Média & Desvio Padrão & Mínimo & Máximo \\
\hline Receita Total & 532 & 774.213 & 1.559 .987 & 2.040 .420 & 12.552 & 14.000 .000 \\
\hline Ativo Total & 537 & 1.500 .000 & 2.761 .722 & 3.363 .116 & 88.379 & 17.000 .000 \\
\hline Lucro Líquido & 562 & 72.545 & 169.475 & 252.487 & 0 & 1.400 .000 \\
\hline Ebitda & 518 & 151.195 & 326.940 & 429.388 & 0 & 2.300 .000 \\
\hline Capex & 478 & 119.976 & 293.812 & 413.550 & 0 & 1.923 .130 \\
\hline Tamanho & 501 & 13,67 & 13,74 & 1,24 & 10,60 & 16,60 \\
\hline Crescimento & 411 & 0,17 & 0,31 & 0,46 & $-0,39$ & 2,81 \\
\hline Roa & 501 & 0,10 & 0,13 & 0,09 & 0,00 & 0,55 \\
\hline Mtb & 870 & 1,86 & 1,91 & 0,57 & 1,00 & 4,72 \\
\hline Alavancagem & 526 & 0,54 & 0,56 & 0,25 & 0,12 & 1,45 \\
\hline Painel B: Empresas que não realizaram IPO & & & & \\
\hline Variável & Observações & Mediana & Média & Desvio Padrão & Mínimo & Máximo \\
\hline Receita Total & 2450 & 1.100 .000 & 1.797 .696 & 2.006 .223 & 159.351 & 14.000 .000 \\
\hline Ativo Total & 2450 & 879.021 & 1.734 .353 & 2.334 .266 & 73.294 & 17.000 .000 \\
\hline Lucro Líquido & 2421 & 39.164 & 94.594 & 212.528 & -542.315 & 1.400 .000 \\
\hline Ebitda & 2301 & 96.992 & 209.461 & 331.222 & -157.557 & 2.400 .000 \\
\hline Capex & 1886 & 8.567 & 62.139 & 230.488 & -730.170 & 1.988 .357 \\
\hline Tamanho & 2.166 & 14,14 & 14,31 & 0,69 & 12,06 & 16,68 \\
\hline Crescimento & 1650 & 0,06 & 0,10 & 0,28 & $-0,42$ & 2,83 \\
\hline Roa & 2033 & 0,12 & 0,14 & 0,12 & $-0,12$ & 0,60 \\
\hline Mtb & 2457 & 1,88 & 1,90 & 0,47 & 1,00 & 4,72 \\
\hline Alavancagem & 2154 & 0,68 & 0,69 & 0,27 & 0,11 & 1,45 \\
\hline
\end{tabular}

Fonte: Economática e MM.

Tabela A3 - Matriz de correlação

\begin{tabular}{|l|c|c|c|c|c|c|}
\hline & Tamanho & Crescimento & ROA & CAPEX & Alavancagem & MTB \\
\hline Tamanho & 1,00 & & & & & \\
Crescimento & $-0,23$ & 1,00 & & & & \\
ROA & 0,03 & $-0,12$ & 1,00 & & & \\
CAPEX & 0,12 & 0,16 & 0,03 & 1,00 & & \\
Alavancagem & 0,09 & $-0,08$ & $-0,10$ & $-0,11$ & 1,00 & \\
MTB & $-0,04$ & 0,02 & 0,02 & $-0,02$ & 0,05 & 1,00 \\
\hline
\end{tabular}

Fonte: Economática e MM. 
Tabela A4 - Teste de balanceamento do propensity score matching

\begin{tabular}{|l|l|c|c|c|c|c|c|}
\hline Painel A: Testes de média e redução de viés \\
\hline Variável & Amostra & $\begin{array}{c}\text { Média dos } \\
\text { tratados }\end{array}$ & $\begin{array}{c}\text { Média do } \\
\text { controle }\end{array}$ & $\mathbf{t}$ & $\mathbf{p}>\mathbf{t}$ & \% Viés & $\begin{array}{c}\text { \% Redução } \\
\text { do viés }\end{array}$ \\
\hline \multirow{2}{*}{ Tamanho } & Unmatched & 13,562 & 14,249 & $-5,47$ & 0,000 & $-69,0$ & \\
& Matched & 14,053 & 14,052 & 0,01 & 0,995 & 0,2 & 99,8 \\
\hline \multirow{2}{*}{ Crescimento } & Unmatched & 0,225 & 0,105 & 3,07 & 0,002 & 48,2 & \\
& Matched & 0,139 & 0,133 & 0,08 & 0,935 & 2,2 & 95,4 \\
\hline \multirow{2}{*}{ ROA } & Unmatched & 0,171 & 0,145 & 1,46 & 0,144 & 23,4 & \\
& Matched & 0,168 & 0,178 & $-0,26$ & 0,793 & $-9,0$ & 61,3 \\
\hline \multirow{2}{*}{ Capex } & Unmatched & 270.000 & 53.939 & 6,54 & 0,000 & 75,1 & \\
& Matched & 160.000 & 190.000 & $-0,33$ & 0,742 & $-8,7$ & 88,5 \\
\hline \multirow{2}{*}{ MTB } & Unmatched & 2,244 & 2,011 & 3,1 & 0,002 & 48,4 & \\
& Matched & 2,144 & 2,021 & 0,88 & 0,382 & 25,5 & 47,2 \\
\hline \multirow{2}{*}{ Alavancagem } & Unmatched & 0,785 & 0,747 & 0,85 & 0,398 & 15,4 & \\
& Matched & 0,822 & 0,731 & 1,08 & 0,288 & 36,9 & $-13,9$ \\
\hline Painel B: Pseudo R antes e depois de efetuar o matching \\
\hline Pré-matching \\
Pós-matching
\end{tabular}

Fonte: Elaboração própria. 
Tabela A5 - ATT estimado em termos de diferentes medidas de performance 2004

\begin{tabular}{|c|c|c|c|c|c|c|c|}
\hline \multirow{2}{*}{ Período } & \multirow{2}{*}{ ATT } & \multirow{2}{*}{$\begin{array}{c}\text { Erro } \\
\text { Padrão }\end{array}$} & \multirow{2}{*}{$\begin{array}{c}\text { Estatística } \\
t\end{array}$} & \multicolumn{2}{|c|}{ Off Support } & \multicolumn{2}{|c|}{ Common Support } \\
\hline & & & & Não-Tratado & Tratado & Não-Tratado & Tratado \\
\hline \multicolumn{8}{|c|}{ Painel A: Retorno Operacional dos Ativos (ROA) } \\
\hline 1 & -0.05901 & 0.11076 & -0.53277 & 0 & 1 & 158 & 5 \\
\hline 2 & 0.00814 & 0.10122 & 0.08038 & 0 & 1 & 132 & 4 \\
\hline 3 & -0.00441 & 0.10611 & -0.04159 & 0 & 1 & 114 & 4 \\
\hline \multicolumn{8}{|c|}{ Painel B: Retorno Operacional das Vendas (RSV) } \\
\hline 1 & 0.03497 & 0.09132 & 0.38291 & 0 & 1 & 160 & 5 \\
\hline 2 & 0.04696 & 0.10775 & 0.43579 & 0 & 1 & 133 & 4 \\
\hline 3 & 0.08066 & 0.11575 & 0.69686 & 0 & 1 & 116 & 4 \\
\hline \multicolumn{8}{|c|}{ Painel C: Retorno Operacional dos Lucros (ROE) } \\
\hline 1 & -0.05543 & 0.08396 & -0.66016 & 0 & 1 & 159 & 5 \\
\hline 2 & -0.03154 & 0.07418 & -0.42510 & 0 & 1 & 132 & 5 \\
\hline 3 & -0.01110 & 0.07545 & -0.14712 & 0 & 1 & 115 & 4 \\
\hline \multicolumn{8}{|c|}{ Painel D: Rotatividade dos Ativos (GIRO) } \\
\hline 1 & -0.73897 & 0.58097 & -1.27196 & 0 & 1 & 160 & 5 \\
\hline 2 & -0.60922 & 0.50012 & -1.21814 & 0 & 1 & 132 & 5 \\
\hline 3 & -0.57778 & 0.55064 & -1.04929 & 0 & 1 & 117 & 5 \\
\hline \multicolumn{8}{|c|}{ Painel E: Grau de Endividamento (DEBT) } \\
\hline 1 & -0.14621 & 0.09073 & -1.61152 & 0 & 1 & 162 & 5 \\
\hline 2 & -0.16897 & 0.11107 & -1.52138 & 0 & 0 & 135 & 3 \\
\hline 3 & -0.11553 & 0.12436 & -0.92907 & 0 & 0 & 120 & 6 \\
\hline \multicolumn{8}{|c|}{ Painel F: Investimento em Capital Fixo (CAPEX) } \\
\hline 1 & 0.04085 & 0.07637 & 0.53489 & 0 & 1 & 158 & 5 \\
\hline 2 & 0.04284 & 0.08018 & 0.53433 & 0 & 0 & 131 & 5 \\
\hline 3 & 0.04253 & 0.10625 & 0.40033 & 0 & 1 & 117 & 5 \\
\hline
\end{tabular}

Esta tabela documenta o average treatment effect (ATT) para a performance pós-IPO referente ao ano de 2004. O período 1, 2 e 3 refere-se ao desempenho em 2005, 2006 e 2007, respectivamente. Os painéis AF referem-se ao retorno operacional nos ativos (ROA), retorno operacional nas vendas (OROS), retorno operacional nos lucros (RSV), asset turnover (GIRO), razão dívida por ativo (DEBT) e Investimento (CAPEX). A segunda coluna evidencia as estimativas do ATT. Os erros-padrão foram calculados utilizando 200 repetições via bootstrap. Common support refere-se ao conjunto de firmas no qual o propensity score sobrepõe-se entre os controles (não-IPO) e tratados (IPOs). Off support refere-se ao número de tratados (IPOs) no qual o propensity score fica acima do valor máximo e abaixo do valor mínimo das firmas de controle (não-IPOs).

***,**,* referem-se à significância estatística ao nível de $0,01,0,05$ e 0,10 respectivamente. 
Tabela A6 - ATT estimado em termos de diferentes medidas de performance 2005

\begin{tabular}{|c|c|c|c|c|c|c|c|}
\hline \multirow{2}{*}{ Período } & \multirow{2}{*}{ ATT } & \multirow{2}{*}{$\begin{array}{c}\text { Erro } \\
\text { Padrão }\end{array}$} & \multirow{2}{*}{$\begin{array}{c}\text { Estatística } \\
t\end{array}$} & \multicolumn{2}{|c|}{ Off Support } & \multicolumn{2}{|c|}{ Common Support } \\
\hline & & & & Não-Tratado & Tratado & Não-Tratado & Tratado \\
\hline \multicolumn{8}{|c|}{ Painel A: Retorno Operacional dos Ativos (ROA) } \\
\hline 1 & 0.05429 & 0.08025 & 0.67655 & 0 & 4 & 151 & 3 \\
\hline 2 & -0.10756 & 0.07136 & -1.50732 & 0 & 4 & 135 & 3 \\
\hline 3 & -0.05326 & 0.05085 & -1.04749 & 0 & 4 & 106 & 2 \\
\hline \multicolumn{8}{|c|}{ Painel B: Retorno Operacional das Vendas (RSV) } \\
\hline 1 & 0.03155 & 0.08223 & 0.38372 & 0 & 4 & 153 & 3 \\
\hline 2 & -0.15536 & 0.09966 & -1.55883 & 0 & 5 & 136 & 4 \\
\hline 3 & -0.00257 & 0.07331 & -0.03501 & 0 & 4 & 105 & 3 \\
\hline \multicolumn{8}{|c|}{ Painel C: Retorno Operacional dos Lucros (OROP) } \\
\hline 1 & 0.05196 & 0.06693 & 0.77636 & 0 & 4 & 152 & 4 \\
\hline 2 & -0.02174 & 0.02938 & -0.73978 & 0 & 4 & 137 & 4 \\
\hline 3 & 0.05175 & 0.03495 & 1.48077 & 0 & 4 & 107 & 3 \\
\hline \multicolumn{8}{|c|}{ Painel D: Rotatividade dos Ativos (GIRO) } \\
\hline 1 & -0.38532 & 0.66934 & -0.57567 & 0 & 4 & 153 & 3 \\
\hline 2 & -0.35455 & 0.28376 & -1.24945 & 0 & 4 & 135 & 3 \\
\hline 3 & -0.87719 & 0.22498 & -3.89903 & 0 & 4 & 119 & 2 \\
\hline \multicolumn{8}{|c|}{ Painel E: Grau de Endividamento (DEBT) } \\
\hline 1 & -0.11674 & 0.12456 & -0.93724 & 0 & 4 & 155 & 4 \\
\hline 2 & -0.08163 & 0.12116 & -0.67378 & 0 & 4 & 138 & 3 \\
\hline 3 & -0.29334 & 0.08154 & -3.59769 & 0 & 4 & 112 & 2 \\
\hline \multicolumn{8}{|c|}{ Painel F: Investimento em Capital Fixo (CAPEX) } \\
\hline 1 & 0.01962 & 0.04844 & 0.40498 & 0 & 4 & 152 & 4 \\
\hline 2 & -0.07187 & 0.05789 & -1.24155 & 0 & 5 & 136 & 3 \\
\hline 3 & 0.02789 & 0.03171 & 0.87934 & 0 & 4 & 111 & 4 \\
\hline
\end{tabular}

Esta tabela documenta o average treatment effect (ATT) para a performance pós-IPO referente ao ano de 20045. O período 1, 2 e 3 refere-se ao desempenho em 2006, 2007 e 2008, respectivamente. Os painéis A-F referem-se ao retorno operacional nos ativos (ROA), retorno operacional nas vendas (OROS), retorno operacional nos lucros (RSV), asset turnover (GIRO), razão dívida por ativo (DEBT) e Investimento (CAPEX). A segunda coluna evidencia as estimativas do ATT. Os erros-padrão foram calculados utilizando 200 repetições via bootstrap. Common support refere-se ao conjunto de firmas no qual o propensity score sobrepõe-se entre os controles (não-IPO) e tratados (IPOs). Off support refere-se ao número de tratados (IPOs) no qual o propensity score fica acima do valor máximo e abaixo do valor mínimo das firmas de controle (não-IPOs).

***,**,* referem-se à significância estatística ao nível de 0,01, 0,05 e 0,10 respectivamente. 
Tabela A7 - ATT estimado em termos de diferentes medidas de performance 2006

\begin{tabular}{|c|c|c|c|c|c|c|c|}
\hline \multirow{2}{*}{ Período } & \multirow{2}{*}{ ATT } & \multirow{2}{*}{$\begin{array}{c}\text { Erro } \\
\text { Padrão }\end{array}$} & \multirow{2}{*}{$\begin{array}{c}\text { Estatística } \\
\mathbf{t}\end{array}$} & \multicolumn{2}{|c|}{ Off Support } & \multicolumn{2}{|c|}{ Common Support } \\
\hline & & & & Não-Tratado & Tratado & Não-Tratado & Tratado \\
\hline \multicolumn{8}{|c|}{ Painel A: Retorno Operacional dos Ativos (ROA) } \\
\hline 1 & -0.02725 & 0.03117 & -0.87419 & 0 & 5 & 165 & 7 \\
\hline 2 & -0.01844 & 0.03377 & -0.54618 & 0 & 6 & 128 & 6 \\
\hline 3 & 0.03228 & 0.03853 & 0.83780 & 0 & 7 & 110 & 5 \\
\hline \multicolumn{8}{|c|}{ Painel B: Retorno Operacional das Vendas (RSV) } \\
\hline 1 & 0.05394 & 0.06285 & 0.85823 & 0 & 5 & 167 & 7 \\
\hline 2 & 0.05994 & 0.05439 & 1.10204 & 0 & 6 & 129 & 6 \\
\hline 3 & 0.08934 & 0.05729 & 1.55944 & 0 & 7 & 111 & 5 \\
\hline \multicolumn{8}{|c|}{ Painel C: Retorno Operacional dos Lucros (OROP) } \\
\hline 1 & 0.00745 & 0.02088 & 0.35674 & 0 & 5 & 168 & 7 \\
\hline 2 & 0.00415 & 0.02538 & 0.16344 & 0 & 6 & 132 & 6 \\
\hline 3 & 0.00292 & 0.03237 & 0.09030 & 0 & 7 & 115 & 5 \\
\hline \multicolumn{8}{|c|}{ Painel D: Rotatividade dos Ativos (GIRO) } \\
\hline 1 & -0.46177 & 0.43156 & -1.07001 & 0 & 5 & 170 & 7 \\
\hline 2 & -0.51156 & 0.47579 & -1.07519 & 0 & 6 & 132 & 6 \\
\hline 3 & -0.41469 & 0.55651 & -0.74516 & 0 & 5 & 113 & 5 \\
\hline \multicolumn{8}{|c|}{ Painel E: Grau de Endividamento (DEBT) } \\
\hline 1 & -0.03674 & 0.10270 & -0.35773 & 0 & 5 & 173 & 7 \\
\hline 2 & -0.15007 & 0.09414 & -1.59404 & 0 & 6 & 135 & 6 \\
\hline 3 & -0.06810 & 0.09872 & -0.68979 & 0 & 6 & 117 & 5 \\
\hline \multicolumn{8}{|c|}{ Painel F: Investimento em Capital Fixo (CAPEX) } \\
\hline 1 & 0.02606 & 0.04652 & 0.56022 & 0 & 6 & 170 & 5 \\
\hline 2 & 0.06108 & 0.04982 & 1.22617 & 0 & 6 & 131 & 6 \\
\hline 3 & 0.00656 & 0.06673 & 0.09836 & 0 & 4 & 107 & 7 \\
\hline
\end{tabular}

Esta tabela documenta o average treatment effect (ATT) para a performance pós-IPO referente ao ano de 2006. O período 1, 2 e 3 refere-se ao desempenho em 2007, 2008 e 2009, respectivamente. Os painéis AF referem-se ao retorno operacional nos ativos (ROA), retorno operacional nas vendas (OROS), retorno operacional nos lucros (RSV), asset turnover (GIRO), razão dívida por ativo (DEBT) e Investimento (CAPEX). A segunda coluna evidencia as estimativas do ATT. Os erros-padrão foram calculados utilizando 200 repetições via bootstrap. Common support refere-se ao conjunto de firmas no qual o propensity score sobrepõe-se entre os controles (não-IPO) e tratados (IPOs). Off support refere-se ao número de tratados (IPOs) no qual o propensity score fica acima do valor máximo e abaixo do valor mínimo das firmas de controle (não-IPOs).

***,**,* referem-se à significância estatística ao nível de $0,01,0,05$ e 0,10 respectivamente. 
Tabela A8 - ATT estimado em termos de diferentes medidas de performance 2007

\begin{tabular}{|c|c|c|c|c|c|c|c|}
\hline \multirow{2}{*}{ Período } & \multirow{2}{*}{ ATT } & \multirow{2}{*}{$\begin{array}{c}\text { Erro } \\
\text { Padrão }\end{array}$} & \multirow{2}{*}{$\begin{array}{c}\text { Estatística } \\
t\end{array}$} & \multicolumn{2}{|c|}{ Off Support } & \multicolumn{2}{|c|}{ Common Support } \\
\hline & & & & Não-Tratado & Tratado & Não-Tratado & Tratado \\
\hline \multicolumn{8}{|c|}{ Painel A: Retorno Operacional dos Ativos (ROA) } \\
\hline 1 & 0.00553 & 0.10218 & 0.05413 & 0 & 7 & 154 & 5 \\
\hline 2 & 0.05884 & 0.08033 & 0.73247 & 0 & 7 & 136 & 5 \\
\hline 3 & -0.00702 & 0.04837 & -0.14509 & 0 & 7 & 108 & 4 \\
\hline \multicolumn{8}{|c|}{ Painel B: Retorno Operacional das Vendas (RSV) } \\
\hline 1 & -0.09926 & 0.06815 & -1.45635 & 0 & 7 & 155 & 5 \\
\hline 2 & -0.00965 & 0.09122 & -0.10577 & 0 & 7 & 137 & 5 \\
\hline 3 & -0.07072 & 0.05148 & -1.37390 & 0 & 7 & 107 & 3 \\
\hline \multicolumn{8}{|c|}{ Painel C: Retorno Operacional dos Lucros (OROP) } \\
\hline 1 & 0.18769 & 0.14574 & 1.28778 & 0 & 6 & 160 & 6 \\
\hline 2 & 0.00347 & 0.03955 & 0.08779 & 0 & 6 & 140 & 7 \\
\hline 3 & -0.01816 & 0.02992 & -0.60707 & 0 & 6 & 110 & 6 \\
\hline \multicolumn{8}{|c|}{ Painel D: Rotatividade dos Ativos (GIRO) } \\
\hline 1 & -0.09103 & 0.37974 & -0.23972 & 0 & 7 & 161 & 6 \\
\hline 2 & -0.19621 & 0.30391 & -0.64561 & 0 & 6 & 140 & 7 \\
\hline 3 & -0.47122 & 0.38377 & -1.22789 & 0 & 7 & 111 & 4 \\
\hline \multicolumn{8}{|c|}{ Painel E: Grau de Endividamento (DEBT) } \\
\hline 1 & -0.14239 & 0.17332 & -0.82155 & 0 & 7 & 163 & 5 \\
\hline 2 & -0.02662 & 0.22601 & -0.11780 & 0 & 7 & 143 & 6 \\
\hline 3 & -0.00738 & 0.18647 & -0.03958 & 0 & 5 & 116 & 7 \\
\hline \multicolumn{8}{|c|}{ Painel F: Investimento em Capital Fixo (CAPEX) } \\
\hline 1 & 0.02382 & 0.06413 & 0.37143 & 0 & 8 & 159 & 2 \\
\hline 2 & 0.07439 & 0.06153 & 1.20897 & 0 & 7 & 131 & 3 \\
\hline 3 & 0.08318 & 0.05939 & 1.40060 & 0 & 5 & 112 & 5 \\
\hline
\end{tabular}

Esta tabela documenta o average treatment effect (ATT) para a performance pós-IPO referente ao ano de 2007. O período 1, 2 e 3 refere-se ao desempenho em 2008, 2009 e 2010, respectivamente. Os painéis AF referem-se ao retorno operacional nos ativos (ROA), retorno operacional nas vendas (OROS), retorno operacional nos lucros (RSV), asset turnover (GIRO), razão dívida por ativo (DEBT) e Investimento (CAPEX). A segunda coluna evidencia as estimativas do ATT. Os erros-padrão foram calculados utilizando 200 repetições via bootstrap. Common support refere-se ao conjunto de firmas no qual o propensity score sobrepõe-se entre os controles (não-IPO) e tratados (IPOs). Off support refere-se ao número de tratados (IPOs) no qual o propensity score fica acima do valor máximo e abaixo do valor mínimo das firmas de controle (não-IPOs).

***,**,* referem-se à significância estatística ao nível de 0,01, 0,05 e 0,10 respectivamente. 
Tabela A9 - ATT estimado em termos de diferentes medidas de performance 2004-2007

\begin{tabular}{|c|c|c|c|c|c|c|c|}
\hline \multirow{2}{*}{ Período } & \multirow{2}{*}{ ATT } & \multirow{2}{*}{$\begin{array}{c}\text { Erro } \\
\text { Padrão }\end{array}$} & \multirow{2}{*}{$\begin{array}{c}\text { Estatística } \\
\mathbf{t}\end{array}$} & \multicolumn{2}{|c|}{ Off Support } & \multicolumn{2}{|c|}{ Common Support } \\
\hline & & & & Não-Tratado & Tratado & Não-Tratado & Tratado \\
\hline \multicolumn{8}{|c|}{ Painel A: Retorno Operacional dos Ativos (ROA) } \\
\hline 2008 & -0.02797 & 0.04273 & -0.65450 & 0 & 12 & 159 & 22 \\
\hline 2009 & -0.01288 & 0.04174 & -0.30858 & 0 & 12 & 146 & 22 \\
\hline 2010 & 0.02096 & 0.03218 & 0.65125 & 0 & 12 & 127 & 20 \\
\hline \multicolumn{8}{|c|}{ Painel B: Retorno Operacional das Vendas (RSV) } \\
\hline 2008 & 0.00652 & 0.05154 & 0.12658 & 0 & 12 & 160 & 22 \\
\hline 2009 & 0.03490 & 0.06040 & 0.57776 & 0 & 12 & 147 & 22 \\
\hline 2010 & 0.02281 & 0.06080 & 0.37517 & 0 & 12 & 126 & 19 \\
\hline \multicolumn{8}{|c|}{ Painel C: Retorno Operacional dos Lucros (OROP) } \\
\hline 2008 & 0.05270 & 0.03901 & 1.35097 & 0 & 11 & 166 & 25 \\
\hline 2009 & -0.00765 & 0.01841 & -0.41541 & 0 & 10 & 150 & 26 \\
\hline 2010 & 0.00985 & 0.02159 & 0.45612 & 0 & 11 & 129 & 23 \\
\hline \multicolumn{8}{|c|}{ Painel D: Rotatividade dos Ativos (GIRO) } \\
\hline 2008 & -0.34640 & 0.25909 & -1.33698 & 0 & 10 & 167 & 26 \\
\hline 2009 & -0.15085 & 0.20830 & -0.72418 & 0 & 11 & 149 & 25 \\
\hline 2010 & -0.25129 & 0.28266 & -0.88901 & 0 & 12 & 129 & 21 \\
\hline \multicolumn{8}{|c|}{ Painel E: Grau de Endividamento (DEBT) } \\
\hline 2008 & -0.13521 & 0.08210 & -1.64693 & 0 & 11 & 171 & 24 \\
\hline 2009 & -0.07583 & 0.07872 & -0.96330 & 0 & 10 & 154 & 26 \\
\hline 2010 & -0.04229 & 0.07432 & -0.56904 & 0 & 9 & 137 & 21 \\
\hline \multicolumn{8}{|c|}{ Painel F: Investimento em Capital Fixo (CAPEX) } \\
\hline 2008 & 0.06822 & 0.04690 & 1.45463 & 0 & 11 & 167 & 21 \\
\hline 2009 & $0.04317^{*}$ & 0.02414 & 1.78790 & 0 & 7 & 140 & 25 \\
\hline 2010 & $0.04554 * *$ & 0.02122 & 2.14647 & 0 & 10 & 132 & 20 \\
\hline
\end{tabular}

Esta tabela documenta o average treatment effect (ATT) para a performance pós-IPO referente ao período de 2004-2007. Os painéis A-F referem-se ao retorno operacional nos ativos (ROA), retorno operacional nas vendas (RSV), retorno operacional nos lucros (OROP), asset turnover (GIRO), razão dívida por ativo (DEBT) e Investimento (CAPEX). A segunda coluna evidencia as estimativas do ATT. Os erros-padrão foram calculados utilizando 200 repetições via bootstrap. Common support refere-se ao conjunto de firmas no qual o propensity score sobrepõe-se entre os controles (não-IPO) e tratados (IPOs). Off support refere-se ao número de tratados (IPOs) no qual o propensity score fica acima do valor máximo e abaixo do valor mínimo das firmas de controle (não-IPOs).

***,**,* referem-se à significância estatística ao nível de $0,01,0,05$ e 0,10 respectivamente. 
Tabela A10 - ATT estimado em termos de investimento (CAPEX) - 2004-2007

\begin{tabular}{|c|c|c|c|c|c|c|c|}
\hline \multirow{2}{*}{ Período } & \multirow{2}{*}{ ATT } & \multirow{2}{*}{$\begin{array}{c}\text { Erro } \\
\text { Padrão }\end{array}$} & \multirow{2}{*}{$\begin{array}{c}\text { Estatística } \\
\mathbf{t}\end{array}$} & \multicolumn{2}{|c|}{ Off Support } & \multicolumn{2}{|c|}{ Common Support } \\
\hline & & & & Não-Tratado & Tratado & Não-Tratado & Tratado \\
\hline \multicolumn{8}{|c|}{ Painel A: Kernel Matching } \\
\hline 2008 & 0.06822 & 0.04690 & 1.45463 & 0 & 11 & 167 & 21 \\
\hline 2009 & $0.04317 *$ & 0.02414 & 1.78790 & 0 & 7 & 140 & 25 \\
\hline 2010 & $0.04554 * *$ & 0.02122 & 2.14647 & 0 & 10 & 132 & 20 \\
\hline \multicolumn{8}{|c|}{ Painel B: Nearest Neighbor Matching (1) } \\
\hline 2008 & $0.10595 * *$ & 0.04977 & 2.12883 & 0 & 0 & 167 & 32 \\
\hline 2009 & $0.05814 * *$ & 0.02924 & 1.98845 & 0 & 0 & 140 & 32 \\
\hline 2010 & $0.06969 * * *$ & 0.02471 & 2.81966 & 0 & 0 & 132 & 30 \\
\hline \multicolumn{8}{|c|}{ Painel C: Nearest Neighbor Matching (5) } \\
\hline 2008 & $0.11641 * * *$ & 0.04196 & 2.77452 & 0 & 0 & 167 & 32 \\
\hline 2009 & $0.04627 *$ & 0.02374 & 1.94909 & 0 & 0 & 140 & 32 \\
\hline 2010 & $0.06865 * * *$ & 0.02534 & 2.70936 & 0 & 0 & 132 & 30 \\
\hline \multicolumn{8}{|c|}{ Painel D: Caliper Matching } \\
\hline 2008 & 0.07608 & 0.05073 & 1.49974 & 0 & 10 & 167 & 22 \\
\hline 2009 & $0.05470 * *$ & 0.02657 & 2.05908 & 0 & 3 & 140 & 29 \\
\hline 2010 & $0.05590 * *$ & 0.02638 & 2.11872 & 0 & 8 & 132 & 22 \\
\hline \multicolumn{8}{|c|}{ Painel E: Radius Matching } \\
\hline 2008 & 0.06596 & 0.04477 & 1.47313 & 0 & 10 & 167 & 22 \\
\hline 2009 & $0.05269 * *$ & 0.02395 & 2.20036 & 0 & 3 & 140 & 29 \\
\hline 2010 & $0.05438 * *$ & 0.02203 & 2.46835 & 0 & 8 & 132 & 22 \\
\hline \multicolumn{8}{|c|}{ Painel F: Local Linear Regression Matching } \\
\hline 2008 & 0.06662 & 0.04546 & 1.46542 & 0 & 10 & 167 & 22 \\
\hline 2009 & $0.05324 * *$ & 0.02444 & 2.17847 & 0 & 3 & 140 & 29 \\
\hline 2010 & $0.05847 * *$ & 0.02432 & 2.40366 & 0 & 8 & 132 & 22 \\
\hline
\end{tabular}

Esta tabela documenta o average treatment effect (ATT) para a variável investimento (CAPEX) pós-IPO referente ao período de 2004-2007. Os painéis A-F referem-se aos seguintes métodos de matching: kernel, nearest neighbor (1), nearest neighbor (5), caliper, radius e local linear regression, respectivamente. A segunda coluna evidencia as estimativas do ATT para essas distintas metodologias. Os erros-padrão foram calculados utilizando 200 repetições via bootstrap. Common support refere-se ao conjunto de firmas no qual o propensity score sobrepõe-se entre os controles (não-IPO) e tratados (IPOs). Off support refere-se ao número de tratados (IPOs) no qual o propensity score fica acima do valor máximo e abaixo do valor mínimo das firmas de controle (não-IPOs).

***, **, * referem-se à significância estatística ao nível de $0,01,0,05$ e 0,10 respectivamente. 